\title{
Geologia
}

\section{Novas Técnicas Aplicadas ao Método U-Pb no CPGeo - IGc/USP: Avanços na Digestão Química, Espectrometria de Massa (TIMS) e Exemplos de Aplicação Integrada com SHRIMP}

\author{
New Techniques Applied to the U-Pb Method at the Centre for Geochronological \\ Research of the University of São Paulo: Chemical Digestions, TIMS Mass \\ Spectrometry and Examples of Integrated Application of SHRIMP
}

\author{
Kei Sato (keisato@usp.br), Miguel Angelo Stipp Basei (baseimas@usp.br), Oswaldo Siga Júnior (osigair@usp.br), \\ Walter Maurício Sproesser (wmsproes@usp.br), Cláudia Regina Passarelli (crpass@usp.br) \\ Centro de Pesquisas Geocronológicas - Instituto de Geociências - USP \\ R. do Lago 562, CEP 05508-080, São Paulo, SP, BR
}

Recebido em 09 de maio de 2007; aceito em 01 de agosto de 2008

Palavras-chave: zircão, geocronologia, $\varepsilon_{\mathrm{H}}$, forno de microondas, spike ${ }^{205} \mathrm{~Pb}$, microcoluna, lixiviamento.

\section{RESUMO}

O presente trabalho tem como principal objetivo apresentar novas técnicas relativas ao método geocronológico U-Pb, principalmente em zircão, utilizadas no CPGeo-IGc/USP. Trata-se de um método que vem sendo constantemente aprimorado desde sua implantação na década de 90. Técnicas de separação ou concentração de zircão, digestão química parcial e total envolvendo lixiviamento e dissolução completa, concentrações de U e Pb em microcolunas de troca aniônica, utilização de spike ${ }^{205} \mathrm{~Pb}$, bem como equações de cálculo de idade são comentadas. À guisa de exemplo, são discutidas aplicações de dados isotópicos $\mathrm{U}-\mathrm{Pb}$, obtidos em zircão com heranças isotópicas (presença de núcleo e borda), envolvendo técnicas de lixiviamento e forno de microondas convencional. Estudos relativos à gênese de zircão com base em isótopos de ${ }^{176} \mathrm{Hf} /{ }^{177} \mathrm{Hf}$ inicial complementam este trabalho. Por último, encontram-se totalmente desenvolvidas nos anexos, as formulações matemáticas utilizadas no programa PBDAT.

Keywords: zircon, geochronology, $\varepsilon_{\mathrm{H}}$, microwave oven, spike ${ }^{205} \mathrm{~Pb}$, micro column, leaching.

\begin{abstract}
The present work describes new techniques of U-Pb ID-TIMS developed at the CPGeo-IGc/USP. Techniques of partial and total chemical digestions, $\mathrm{U}$ and $\mathrm{Pb}$ concentration using anion exchange in a micro column, and the utilization of a ${ }^{205} \mathrm{~Pb}$ spike are discussed. Main geochronological equations used are also discussed. Examples of the application of U-Pb data, obtained by leaching technique using a microwave oven in zircon with isotopic inheritances in the core and border, are presented. The genesis of zircon based on the initial ${ }^{176} \mathrm{Hf} /{ }^{177} \mathrm{Hf}$ ratio is discussed. Finally complete listings of the mathematical formulations used in the PBDAT software are given in the appendix.
\end{abstract}




\section{INTRODUÇÃO}

O método geocronológico U-Pb, implantado na década de 90 (Basei et al., 1995) junto ao Centro de Pesquisas Geocronológicas da Universidade de São Paulo, passou, desde então, por inúmeras modificações visando a melhoria dos resultados analíticos. As dificuldades iniciais relacionavamse principalmente ao elevado nível de contaminação de $\mathrm{Pb}$ laboratorial, que era algo entre 50 a 100 pg (picogramas). Para minimizar tal efeito, era necessário trabalhar com multicristais de zircão (50 a 150 cristais, dependendo da idade). O emprego de multicristais de zircão nem sempre produzia resultados satisfatórios, pois dependia em muito das características do mesmo (com ou sem sobrecrescimento, metamíctico, fraturado, com inclusões, entre outros). Na ocasião, utilizava-se também o spike ${ }^{208} \mathrm{~Pb}$ para obtenção da concentração do $\mathrm{Pb}$ e do ${ }^{235} \mathrm{U}$ para determinação do teor de $\mathrm{U}$ por meio de diluição isotópica. Com o emprego de spike ${ }^{208} \mathrm{~Pb}$ era necessário trabalhar na forma de duas alíquotas após a digestão química. Uma, utilizada para a determinação da composição isotópica (CI) do $\mathrm{Pb}$ presente no zircão, e outra para determinação da concentração deste elemento químico por diluição isotópica (DI). Tal procedimento duplicava o tempo gasto, tanto no laboratório químico, como nas medidas por espectrometria de massa. As técnicas utilizadas atualmente, após atingir teores de $\mathrm{Pb}$ contaminante da ordem de 2 a 8 pg e a utilização do spike ${ }^{205} \mathrm{~Pb}$, que dispensa a divisão de amostras em alíquotas, aumentaram as precisões nas análises isotópicas de $\mathrm{Pb}$ e U e diminui o tempo gasto na obtenção dos resultados. Tais condições permitem atualmente efetuar análises em poucos ou mesmo em um único cristal de zircão selecionado criteriosamente, reduzindo drasticamente os problemas inerentes ao próprio grão. Adicionalmente, o refinamento analítico, a exemplo dos processos envolvendo a lixiviação de zircão por etapas, permitiram um avanço significativo na precisão e na qualidade da interpretação dos dados analíticos U-Pb obtidos no laboratório do CPGeo/USP. Por fim, embora o método Lu-Hf esteja ainda no início implantação, foi introduzido aqui o parâmetro $\varepsilon_{\mathrm{Hf}}$ por tratar-se de vital importância nos estudos da gênese do zircão.

\section{PRINCÍPIOS DA GEOCRONOLOGIA}

\section{Generalidades}

Nuclídeos radioativos naturais referem-se às partículas em estado energético metaestável e que se desintegram espontaneamente com o tempo, emitindo radiações eletromagnéticas e partículas nucleares (alfa, beta', beta+), e/ou capturando elétrons da órbita $\mathrm{K}$ (captura $\mathrm{K}$ ). $\mathrm{O}$ produto final da(s) transformação(ões) nuclear(es), que atinge o estado fundamental (energia mínima) é o nuclídeo radiogênico.
A equação fundamental da geocronologia é baseada no processo físico de decaimento radioativo, definido por uma equação exponencial negativa (Figura 1), que pode ser expressa da seguinte forma:

$$
\begin{aligned}
& \mathrm{N}=\mathrm{N}_{0} \mathrm{e}^{-\lambda \mathrm{T}} \text { ou } \\
& \mathrm{T}=(1 / \lambda) \ln \left(\mathrm{N}_{0} / \mathrm{N}\right) \\
& \text { se } \mathrm{N}_{0}=\mathrm{N}+\mathrm{F} \text { então } \\
& \mathrm{T}=(1 / \lambda) \ln [1+(\mathrm{F} / \mathrm{N})]
\end{aligned}
$$

onde $\lambda$ = constante de desintegração (definida pela probabilidade de decaimento radioativo); $\mathrm{N}$ = número de nuclídeos de um determinado elemento radioativo medido hoje na amostra; $\mathrm{N}_{0}=$ número inicial do nuclídeo radioativo no momento do fechamento do sistema; $\mathrm{F}=\mathrm{N}^{0}$ de átomos transmutados (filho - radiogênico); $\mathrm{T}$ = tempo geológico.

F é igual ao número de átomos que foram transmutados que, na prática, é igual à quantidade inicial de átomos $\left(\mathrm{N}_{0}\right)$ menos a quantidade total de átomos presentes $(\mathrm{N})$ no sistema no momento de seu fechamento $\left(\mathrm{F}=\mathrm{N}_{0}-\mathrm{N}\right)$. O tempo gasto para que a metade da quantidade inicial de um determinado nuclídeo radioativo se transforme é denominado de meia vida $\left(T_{1 / 2}\right)$. A relação entre a constante $\lambda$ e $T_{1 / 2}$ pode ser escrita da seguinte forma:

$$
\mathrm{T}_{1 / 2}=(\operatorname{Ln} 2) / \lambda
$$

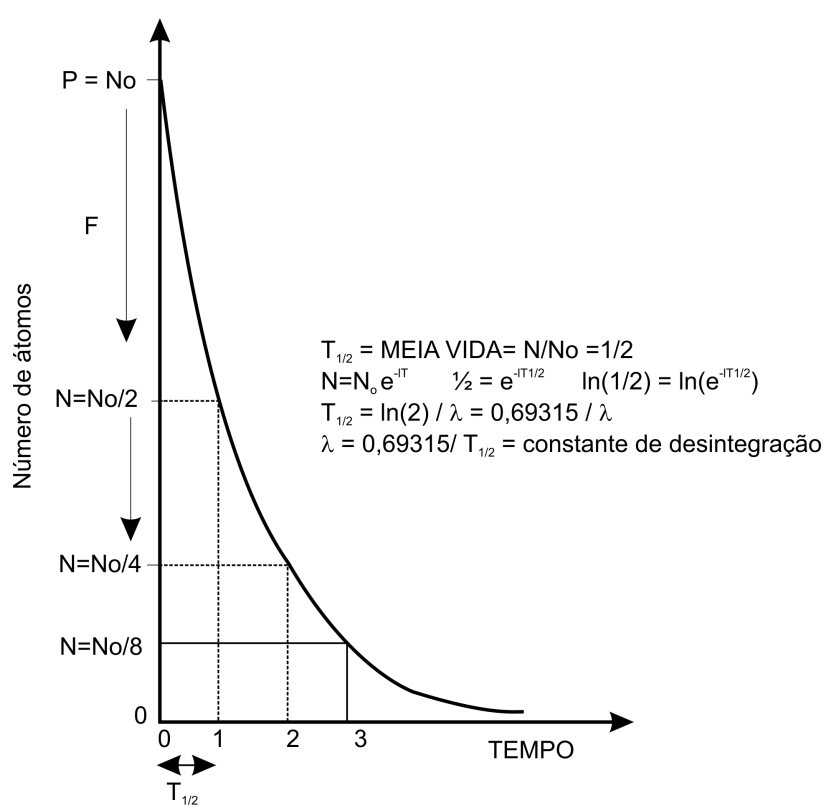

Figura 1. Diagrama esquemático do decaimento radioativo que evolui na forma exponencial negativa ao longo do tempo geológico. 
Para que uma datação, com base no decaimento radioativo, tenha significado geológico é necessário que a quantidade inicial de átomos do elemento filho seja conhecida, ou possa ser calculada, e também que o sistema tenha permanecido fechado tanto nos isótopos do elemento radioativo (pai = N) quanto nos radiogênicos ( $\mathrm{F}=$ filho), exceto partículas transmutadas pelo processo de decaimento radioativo.

Os isótopos radioativos naturais de interesse nos estudos relacionados à evolução geológica devem possuir meias-vidas da mesma ordem de grandeza do tempo geológico (bilhões de anos) e serem suficientemente abundantes na natureza, em diversos tipos de rocha. Tradicionalmente, os métodos radiométricos mais utilizados em geocronologia são: Sm-Nd, Rb-Sr, K-Ar e sua variante Ar-Ar, Re-Os, Lu-Hf e finalmente o que nos interessa neste trabalho, os métodos $\mathrm{U}-\mathrm{Th}-\mathrm{Pb}$ e sua variante $\mathrm{Pb}-\mathrm{Pb}$ (Tabela 1 ).

\section{SISTEMÁTICA U-Pb}

\section{Radioatividade}

O método U-Pb é o único a oferecer dois cronômetros radioativos independentes para um mesmo par de elementos de um único material $\left({ }^{238} \mathrm{U} \rightarrow{ }^{206} \mathrm{~Pb} \mathrm{e}^{235} \mathrm{U} \rightarrow{ }^{207} \mathrm{~Pb}\right)$. Os decaimentos radioativos de $\mathrm{U}$ e Th para isótopos estáveis de $\mathrm{Pb}$ passam por diversas etapas de transição intermediária (séries radioativas naturais), sendo $8 \alpha+6 \beta^{-}$para ${ }^{238} \mathrm{U}, 7 \alpha+4 \beta^{-}$para ${ }^{235} \mathrm{U}$ e $6 \alpha+4 \beta$ para ${ }^{232} \mathrm{Th}$. As séries de transição intermediária destes dois elementos radioativos podem ser observadas abaixo:

$$
\begin{aligned}
& { }^{238} \mathrm{U}_{92} \rightarrow{ }^{234} \mathrm{Th}_{90} \rightarrow{ }^{234} \mathrm{~Pa}_{91} \rightarrow{ }^{234} \mathrm{U}_{92} \rightarrow \\
& { }^{230} \mathrm{Th}_{90} \rightarrow{ }^{226} \mathrm{Ra}_{88} \rightarrow{ }^{222} \mathrm{Rn}_{86} \rightarrow{ }^{218} \mathrm{Po}_{84} \rightarrow \\
& { }^{214} \mathrm{~Pb}_{82} \rightarrow{ }^{214} \mathrm{Bi}_{83} \rightarrow{ }^{214} \mathrm{Po}_{84} \rightarrow{ }^{210} \mathrm{~Pb}_{92} \rightarrow \\
& { }^{210} \mathrm{Bi}_{83} \rightarrow{ }^{210} \mathrm{Po}_{84} \rightarrow{ }^{206} \mathrm{~Pb}_{82} \\
& \left.\begin{array}{l}
{ }^{235} \mathrm{U}_{92} \rightarrow{ }^{231} \mathrm{Th}_{90} \rightarrow{ }^{231} \mathrm{~Pa}_{91} \rightarrow{ }^{227} \mathrm{Ac}_{89} \rightarrow \\
{ }^{223} \mathrm{Fr}_{87} \rightarrow{ }^{223} \mathrm{Ra}_{88} \rightarrow{ }^{219} \mathrm{Rn}_{86} \rightarrow{ }^{215} \mathrm{Po}_{84} \rightarrow \\
{ }^{211} \mathrm{~Pb}_{82} \rightarrow{ }^{211} \mathrm{Bi}_{83} \rightarrow{ }^{211} \mathrm{Po}_{84} \rightarrow{ }^{207} \mathrm{~Pb}_{82}
\end{array}\right] \\
& \left.\begin{array}{l}
{ }^{232} \mathrm{Th}_{90} \rightarrow{ }^{228} \mathrm{Ra}_{88} \rightarrow{ }^{228} \mathrm{Ac}_{89} \rightarrow{ }^{228} \mathrm{Th}_{90} \rightarrow \\
{ }^{224} \mathrm{Ra}_{88} \rightarrow{ }^{220} \mathrm{Rn}_{86} \rightarrow{ }^{216} \mathrm{Po}_{84} \rightarrow{ }^{212} \mathrm{~Pb}_{82} \rightarrow
\end{array}\right]
\end{aligned}
$$$$
\left(8 \alpha+6 \beta^{-}\right)
$$

onde $\lambda=\lambda_{1}+\lambda_{2}+\lambda_{3}+\ldots .+\lambda_{\mathrm{n}}$

A partir da equação 1 podemos escrever as seguintes expressões:

$$
\begin{aligned}
& { }^{206} \mathrm{~Pb}={ }^{206} \mathrm{~Pb}_{0}+{ }^{238} \mathrm{U}_{\mathrm{e}^{-\lambda 1 \mathrm{~T}}} \\
& { }^{207} \mathrm{~Pb}={ }^{207} \mathrm{~Pb}_{0}+{ }^{235} \mathrm{U}_{\mathrm{e}^{-\lambda 2 \mathrm{~T}}} \\
& { }^{208} \mathrm{~Pb}={ }^{208} \mathrm{~Pb}_{0}+{ }^{232} \mathrm{Th}_{\mathrm{e}^{-\lambda 3 \mathrm{~T}}}
\end{aligned}
$$

onde $\mathrm{Pb}_{0}$ é quantidade de $\mathrm{Pb}$ inicial que foi incorporado no sistema na época de cristalização do mineral (fechamento do sistema).

\section{Principais equações utilizadas no método geocronológico U-Pb}

As deduções das equações de cálculo das idades radiométricas para os métodos U-Pb e $\mathrm{Pb}-\mathrm{Pb}$ encontram-se em Faure (1988) e Faure e Mensing (2005). A seguir serão apresentadas apenas as principais equações utilizadas:

Idade ${ }^{206} \mathrm{~Pb} /{ }^{238} \mathrm{U}$

$$
\mathrm{T}_{206}=\left(1 / \lambda_{1}\right) \ln \left[\left({ }^{206} \mathrm{~Pb}_{\mathrm{rad}}{ }^{238} \mathrm{U}\right)+1\right]
$$

Idade ${ }^{207} \mathrm{~Pb} / 235 \mathrm{U}$

$$
\mathrm{T}_{207}=\left(1 / \lambda_{2}\right) \ln \left[\left({ }^{207} \mathrm{~Pb}_{\mathrm{rad}}{ }^{235} \mathrm{U}\right)+1\right]
$$

Idade ${ }^{208} \mathrm{~Pb} /{ }^{232} \mathrm{Th}$

$$
\mathrm{T}_{208}=\left(1 / \lambda_{3}\right) \ln \left[\left({ }^{208} \mathrm{~Pb} \mathrm{rad}^{232} \mathrm{Th}\right)+1\right]
$$

Idade ${ }^{207} \mathrm{~Pb} /{ }^{206} \mathrm{~Pb}$

$$
\left({ }^{207} \mathrm{~Pb} /{ }^{206} \mathrm{~Pb}\right)_{\mathrm{rad}}=(1 / 137,88) \times\left(\mathrm{e}^{\lambda 2 \mathrm{~T}}-1\right) /\left(\mathrm{e}^{\lambda 1 \mathrm{~T}}-1\right)
$$

onde $\lambda_{1}=1,55125 \times 10^{-10} ; \lambda_{2}=9,848510^{-10} ; \lambda_{3}=4,94810^{-10}$; $\mathrm{Pb}_{\text {rad }}=\mathrm{P}_{\text {medido }}-\mathrm{Pb}_{0} \mathrm{e}$

$$
\begin{aligned}
& {\left[\frac{{ }^{207} \mathrm{~Pb}}{{ }^{206} \mathrm{~Pb}}\right]_{\mathrm{rad}}\left[\frac{{ }^{207} \mathrm{~Pb}}{{ }^{206} \mathrm{~Pb}}\right]_{\mathrm{m}}+\left[\frac{{ }^{204} \mathrm{~Pb}}{{ }^{206} \mathrm{~Pb}}\right]_{\mathrm{m}} \times \frac{\left.\left({ }^{207} \mathrm{~Pb} /{ }^{206} \mathrm{~Pb}\right)_{\mathrm{m}}-\left({ }^{207} \mathrm{~Pb} /{ }^{206} \mathrm{~Pb}\right)_{\mathrm{i}} /{ }^{206} \mathrm{~Pb}\right)_{\mathrm{i}}-\left({ }^{204} \mathrm{~Pb} /{ }^{206} \mathrm{~Pb}\right)_{\mathrm{m}}}{\left({ }^{204}\right.}} \\
& \mathrm{SK}_{\mathrm{T}}
\end{aligned}
$$

onde i é a razão inicial de $\mathrm{Pb}$ que varia em função do tempo geológico (Stacey e Kramers, 1975) e m é a razão medida. A dedução matemática da equação 9 pode ser vista no Anexo 1 (equação 25).

$\mathrm{O}$ valor de $\mathrm{SK}_{\mathrm{T}}$ é sempre negativo, qualquer que seja o tempo geológico $\mathrm{T}$, reduzindo, portanto, o valor $\left({ }^{207} \mathrm{~Pb} /{ }^{206} \mathrm{~Pb}\right)_{\text {rad. }}$. Por exemplo, para um dado $\left({ }^{207} \mathrm{~Pb} /{ }^{206} \mathrm{~Pb}\right)_{\mathrm{m}}=$ 0,171645 e $\left({ }^{204} \mathrm{~Pb} /{ }^{206} \mathrm{~Pb}\right)_{\mathrm{m}}=0,001521$ e variando os valores das razões $\left({ }^{207} \mathrm{~Pb} /{ }^{206} \mathrm{~Pb}\right)_{\mathrm{i}}$ e $\left({ }^{204} \mathrm{~Pb} /{ }^{206} \mathrm{~Pb}\right)_{\mathrm{i}}$ em função de $\mathrm{T}$ de Stacey e Kramers (1975), temos o fator $\mathrm{SK}_{\mathrm{T}}$ variando das seguintes formas:

$\mathrm{SK}_{(\mathrm{T}=2,8 \mathrm{Ga})}=(0,19033-1,090) /(0,07462-0,001521)=-12,307$
$\mathrm{SK}_{(\mathrm{T}=2,5 \mathrm{Ga})}=(0,19033-1,056) /(0,07098-0,001521)=-12,463$
$\mathrm{SK}_{(\mathrm{T}=2,0 \mathrm{Ga})}=(0,19033-1,002) /(0,06583-0,001521)=-12,621$
$\mathrm{SK}_{(\mathrm{T}=1,0 \mathrm{Ga})}=(0,19033-0,909) /(0,05860-0,001521)=-12,591$
$\mathrm{SK}_{(\mathrm{T}=0,5 \mathrm{Ga})}=(0,19033-0,870) /(0,05582-0,001521)=-12,517$
$\mathrm{SK}_{(\mathrm{T}=0,0 \text { Ga) }}=(0,19033-0,836) /(0,05348-0,001521)=-12,427$ 
Tabela 1. Elementos radioativos, radiogênicos e parâmetros relativos à desintegração.

\begin{tabular}{ccccc}
\hline Radiotivo & Radiogênico & Decaimento & $\mathrm{T}_{1 / 2}$ (anos) & $\lambda\left(\right.$ anos $^{-1}$ ) \\
\hline${ }^{40} \mathrm{~K}_{19}$ & ${ }^{40} \mathrm{Ar}_{18}$ & cap. elet. & $1,2510^{9}$ & $0,5810^{-10}$ \\
${ }^{40} \mathrm{~K}_{19}$ & ${ }^{40} \mathrm{Ca}_{20}$ & $\beta^{-}$ & $1,39710^{9}$ & $4,96210^{-10}$ \\
${ }^{87} \mathrm{Rb}_{37}$ & ${ }^{87} \mathrm{Sr}_{38}$ & $\beta^{-}$ & $4810^{9}$ & $1,4210^{-11}$ \\
${ }^{176} \mathrm{Lu}_{71}$ & ${ }^{176} \mathrm{Hf}_{72}$ & $\beta^{-}$ & $3510^{9}$ & $1,86710^{-11}$ \\
${ }^{187} \mathrm{Re}_{75}$ & ${ }^{187} \mathrm{Os}_{76}$ & $\beta^{-}$ & $4310^{9}$ & $1,6110^{-11}$ \\
${ }^{147} \mathrm{Sm}_{62}$ & ${ }^{143} \mathrm{Nd}_{60}$ & $\alpha$ & $10610^{9}$ & $0,65410^{-11}$ \\
${ }^{232} \mathrm{Th}_{90}$ & ${ }^{208} \mathrm{~Pb}_{82}$ & $6 \alpha+4 \beta^{-}$ & $1410^{9}$ & $4,94710^{-11}$ \\
${ }^{235} \mathrm{U}_{92}$ & ${ }^{207} \mathrm{~Pb}_{82}$ & $7 \alpha+4 \beta^{-}$ & $0,70410^{9}$ & $9,848510^{-10}$ \\
${ }^{238} \mathrm{U}_{92}$ & ${ }^{206} \mathrm{~Pb}_{82}$ & $8 \alpha+6 \beta^{-}$ & $4,4710^{9}$ & $1,5512510^{-10}$ \\
\hline
\end{tabular}

$\mathrm{O}$ fator $\mathrm{SK}_{\mathrm{T}}$, que envolve as razões $\left({ }^{207} \mathrm{~Pb} /{ }^{206} \mathrm{~Pb}\right)_{\mathrm{m}}$, $\left({ }^{204} \mathrm{~Pb} /{ }^{206} \mathrm{~Pb}\right)_{\mathrm{m}},\left({ }^{207} \mathrm{~Pb} /{ }^{206} \mathrm{~Pb}\right)_{\mathrm{i}}$ e $\left({ }^{204} \mathrm{~Pb} /{ }^{206} \mathrm{~Pb}\right)$, varia na forma de hipérbole com uma faixa muito pequena em relação do tempo geológico $\left[-12,307_{(2,8 \mathrm{Ga})}\right.$ a $-12,427_{(0,0 \mathrm{Ga})}$ com pico de $\left.-12,6_{(2,0 \mathrm{Ga})}\right]$. A correção de $\mathrm{Pb}$ comum, por outro lado, é fortemente dependente do valor da medida de $\left({ }^{204} \mathrm{~Pb} /{ }^{206} \mathrm{~Pb}\right)_{\mathrm{m}}$, ou seja, quanto menor a razão $\left({ }^{204} \mathrm{~Pb} /{ }^{206} \mathrm{~Pb}\right)_{\mathrm{m}}$, menor será a correção na razão de ${ }^{207} \mathrm{~Pb} /{ }^{206} \mathrm{~Pb}$. A correção do $\mathrm{Pb}$ comum inicial será insignificante quando a razão $\left({ }^{204} \mathrm{~Pb} /{ }^{206} \mathrm{~Pb}\right)_{\mathrm{m}}$ for menor que 0,0001 . Quando a razão $\left({ }^{204} \mathrm{~Pb} /{ }^{206} \mathrm{~Pb}\right)_{\mathrm{m}}$ for maior que 0,05 , então a razão $\left({ }^{207} \mathrm{~Pb} /{ }^{206} \mathrm{~Pb}\right)_{\text {rad }}$ calculada a partir de $\left({ }^{207} \mathrm{~Pb} /{ }^{206} \mathrm{~Pb}\right)_{\mathrm{m}}$ poderá sofrer mudanças superiores a $100 \%$, função desta correção. Portanto, a precisão da idade é fortemente dependente da medida da ralação ${ }^{204} \mathrm{~Pb} /{ }^{206} \mathrm{~Pb}(\mathrm{~Pb}$ inicial ou comum) e muito pouco dependente do tempo $\mathrm{T}$ atribuído relativo ao parâmetro $\mathrm{SK}_{\mathrm{T}}$ (Stacey e Kramer, 1975).

As idades $\mathrm{T}$ em função de ${ }^{207} \mathrm{~Pb} /{ }^{206} \mathrm{~Pb}_{\text {rad }}$ (equação 8) podem ser facilmente calculadas com o auxílio de programas de informática de PBDAT (veja no Anexo 1). Por outro lado, mesmo que os procedimentos efetuados sejam analiticamente precisos e devidamente corrigidos (fracionamento isotópico, $\mathrm{Pb}$ inicial e atual), os resultados obtidos só terão significado geológico se o sistema tivesse mantido fechado desde a formação da rocha. Nesses casos as idades ${ }^{206} \mathrm{~Pb} /{ }^{238} \mathrm{U}$ e ${ }^{207} \mathrm{~Pb} /{ }^{235} \mathrm{U}$ e ${ }^{207} \mathrm{~Pb} /{ }^{206} \mathrm{~Pb}$ serão concordantes.

A curva concórdia (Figura 2) representa o lugar geométrico dos pontos com idades concordantes, obtidos pelos dois cronômetros ${ }^{206} \mathrm{~Pb} /{ }^{238} \mathrm{U}$ e ${ }^{207} \mathrm{~Pb} /{ }^{235} \mathrm{U}$. Outro diagrama bastante utilizado refere-se ao TeraWasserburg (Figura 3), no qual se plota os dados ${ }^{238} \mathrm{U} /{ }^{206} \mathrm{~Pb}$ (abscissas) vs ${ }^{207} \mathrm{~Pb} /$ ${ }^{206} \mathrm{~Pb}$ (ordenadas) (ver comentários adicionais na legenda).

Em inúmeros casos, os pontos analíticos se mostram discordantes da curva concórdia, mas alinhados segundo uma reta denominada de discórdia (Figuras 2 e 3). As idades ${ }^{206} \mathrm{~Pb} /{ }^{238} \mathrm{U},{ }^{207} \mathrm{~Pb} /{ }^{235} \mathrm{U}$ e ${ }^{207} \mathrm{~Pb} /{ }^{206} \mathrm{~Pb}$ calculadas com base nas equações 5, 6 e 8, neste caso, se mostram discordantes. A idade obtida pelo intercepto superior da reta discórdia com a curva concórdia pode representar a idade da cristalização dos cristais de zircão. Para o intercepto inferior existem interpretações que relacionam o valor obtido a uma perda de $\mathrm{Pb}$ episódica ou contínua. Se a perda estiver relacionada a um episódio tectônico, a idade obtida para o intercepto inferior pode ser associada ao mesmo e, portanto, ter significado geológico. Por outro lado, se a perda de Pb é contínua, tal como observada em cristais de zircão metamíctico, a idade do intercepto inferior não terá significado geológico.

Gentry et al. (1982) e Kober (1986) apresentaram técnicas distintas de determinação de idades aparentes ${ }^{207} \mathrm{~Pb} /{ }^{206} \mathrm{~Pb}$ utilizando-se da evaporação de $\mathrm{Pb}$ radiogênico diretamente do grão de zircão presa ao filamento de um espectrômetro termo iônico (ver Figura 11b adiante). A Figura 4 refere-se a um diagrama com valores das razões ${ }^{207} \mathrm{~Pb} /{ }^{206} \mathrm{~Pb}$ (ordenada) determinadas através de diversas etapas de evaporação de

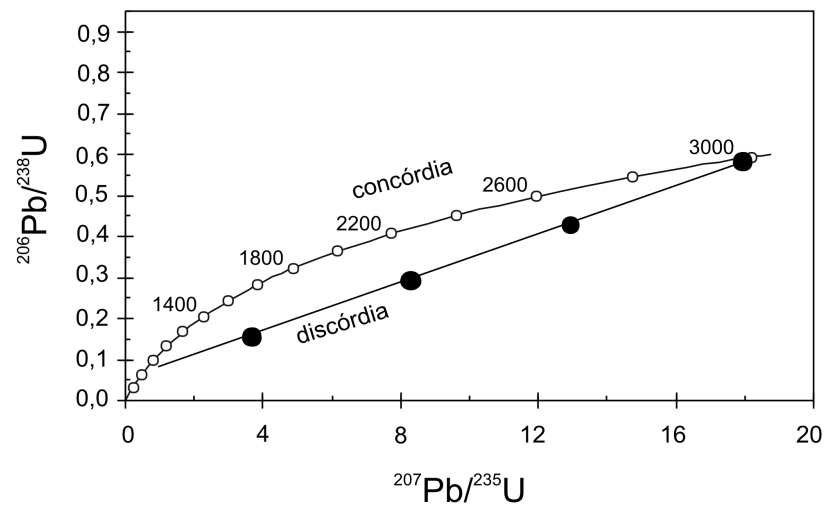

Figura 2. Diagrama concórdia U- $\mathrm{Pb}\left({ }^{206} \mathrm{~Pb} /{ }^{238} \mathrm{U}\right.$ vs. ${ }^{207} \mathrm{~Pb} /{ }^{235} \mathrm{U}$ ). Idades concordantes (pontos analíticos sobre a curva de concórdia); idades discordantes (pontos analíticos posicionados ao longo de uma discórdia). 
zircão com incremento de aquecimento por passo (abscissa). A idade é calculada com base na equação 8. Nesta técnica, o $\mathrm{Pb}$ é evaporado da borda para o núcleo do zircão ou das partes menos retentivas para mais retentivas em cristais fraturados e/ou metamícticos. A Figura 4 mostra a existência de um pequeno patamar em 2380 Ma interpretada como relativa à idade da borda sobrecrescida e um segundo patamar, este bem definido, em 3010 Ma que representa a idade do núcleo do zircão.

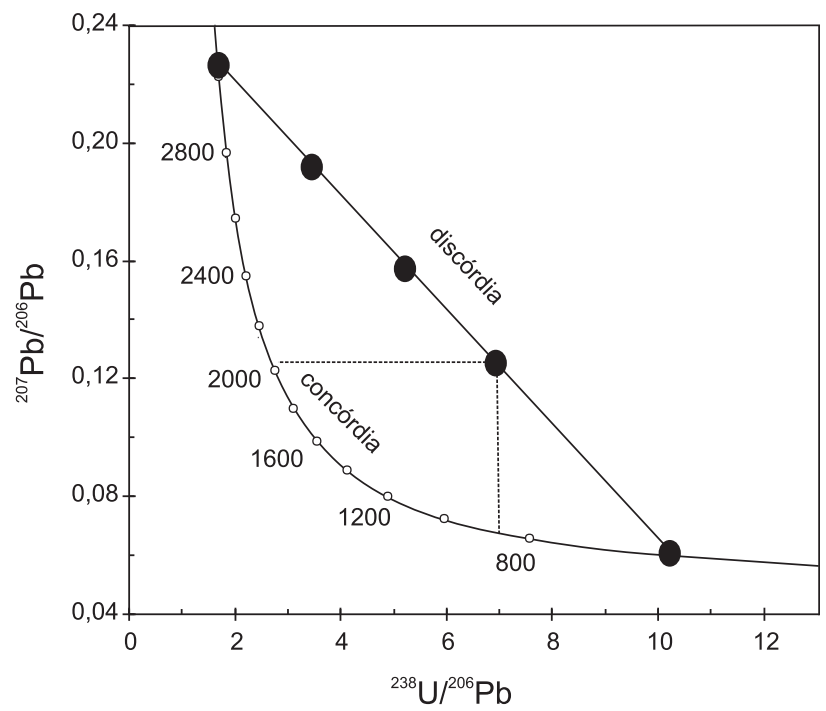

Figura 3. Diagrama de TeraWasserburg - o diagrama envolve a razão ${ }^{207} \mathrm{~Pb} /{ }^{206} \mathrm{~Pb}$ na ordenada e ${ }^{238} \mathrm{U} /{ }^{206} \mathrm{~Pb}$ na abscissa. $O$ emprego deste diagrama é extremamente usual quando o ponto é discordante, pois a ordenada indica a idade ${ }^{207} \mathrm{~Pb} /{ }^{206} \mathrm{~Pb}(2000 \mathrm{Ma}$ - linha horizontal tracejada) e a abscissa indica idade ${ }^{238} \mathrm{U} /{ }^{206} \mathrm{~Pb}(900 \mathrm{Ma}-$ linha vertical tracejada).

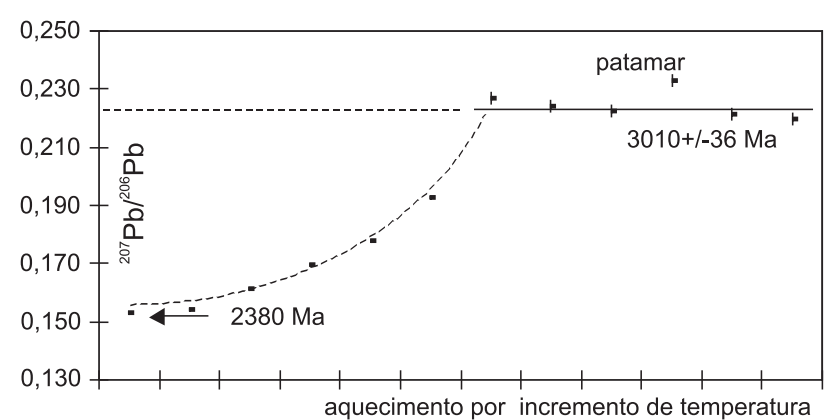

Figura 4. Idades ${ }^{207} \mathrm{~Pb} /{ }^{206} \mathrm{~Pb}$ - método da evaporação $\mathrm{Pb}$ em cristal de zircão por passo. Exemplo da rocha migmatítica (amostra MJ316F) da Pedreira Ita (Sato et al., 2003).

\section{Estudos da gênese do zircão com base nos isótopos de $\mathrm{Hf}$}

Inúmeras datações efetuadas no CPGeo/USP pelo método U-Pb envolveram cristais de zircão provenientes de rochas formadas em diferentes ambientes tectônicos, seja de ruptura ou de colagem de continentes. Para tentar identificar tais ambientes tem grande importância o estudo da gênese do zircão através dos isótopos de Hf.

As composições isotópicas iniciais de Hf no zircão podem refletir a história da magmatogênese (petrogênese) da sua fonte, isto é, se $\varepsilon_{\mathrm{Hf}}$ for maior que zero, implica que material fonte do zircão tem uma origem mantélica. Por outro lado, se $\varepsilon_{\mathrm{Hf}}$ é menor que zero, o material fonte do zircão tem origem crustal. Assim, como nos métodos Rb-Sr, Sm-Nd e Pb-Pb, onde temos respectivamente ${ }^{87} \mathrm{Sr} /{ }^{86} \mathrm{Sr}$ inicial (RI), $\varepsilon_{\mathrm{Nd}}$ inicial e $\mu_{1}$ como traçadores petrogenéticos naturais, o parâmetro $\varepsilon_{\mathrm{Hf}}$ inicial em zircão representa uma importante ferramenta no estudo relativo à evolução da crosta continental.

\section{MATERIAIS UTILIZADOS NO MÉTODO GEOCRONOLÓGICO U-Pb}

Os minerais de maior interesse para a aplicação do método U-Pb são aqueles que contêm U (compatível à estrutura cristalina) e apresentam teores de Pb primário (incompatível à estrutura cristalina) não significativos. Tais minerais são geralmente acessórios de rochas ígneas e metamórficas, a exemplo do zircão, baddeleyita, monazita, titanita e rutilo. $\mathrm{O}$ zircão é o preferido, pois além de conter teores de $\mathrm{U}$ e $\mathrm{Pb}$ radiogênico em quantidades mensuráveis (10 - 1.000 ppm), contém pouco $\mathrm{Pb}$ primário.

\section{Zircão e baddeleyita}

O zircão é um silicato de zircônio, enquanto que a baddeleyita é um óxido de zircônio. O zircão é um mineral acessório de rochas ígneas e metamórficas, predominando nos litotipos félsicos a intermediários. A baddeleyita é mais freqüente em rochas alcalinas, podendo ocorrer em litotipos de natureza máfica. Estes minerais são altamente refratários, resistindo aos mais variados ambientes geológicos. O zircão resiste às altas temperaturas $\left(\sim 800^{\circ} \mathrm{C}\right)$ podendo, no entanto, perder $\mathrm{Pb}$ por processo de metamictização. A metamictização é resultado de danos no retículo cristalino causado durante a liberação de energia nos decaimentos radioativos de U e Th para $\mathrm{Pb}$. Quanto maior a quantidade de U e Th existente nos cristais e quanto mais antigo for o mesmo, maior será o grau de metamictização. Nesse processo, canais abertos propiciam o escape de $\mathrm{Pb}$ radiogênico, no entanto, também pode ocorrer uma pequena entrada de $\mathrm{Pb}$ comum no sistema. Durante a cristalização do zircão e da baddeleyita a quan- 
tidade de $\mathrm{Pb}$ primário incorporado é muito pequena, pois, este elemento é incompatível nesses tipos de minerais, no entanto, freqüentemente observa-se a presença de $\mathrm{Pb}$ inicial em quantidades não desprezíveis.

A Figura 5 mostra imagens de catodoluminescência (CL) de diferentes tipologias de zircão formados em diversos ambientes tectônicos. Os cristais numerados de 1 a 11 foram concentrados das rochas granitóides, enquanto os cristais de 12 a 14 são provenientes de rochas máficas e o cristal 15 representa uma apatita. A imagem de apatita em luz transmitida pode ser facilmente confundida com o zircão, pois em alguns casos mostram hábitos muito similares. A apatita de uma forma em geral apresenta um aspecto mais transparente e brilhante em relação ao zircão. Os zircões de 1 a 3 mostram bandas de zoneamento claras e escuras relativamente regulares que nada mais são as variações dos teores químicos de $U$. Nos cristais 8, 9 e 10 observam-se duas fases de crescimento, destacando-se o núcleo e bordas de sobrecrescimento formadas em épocas tardias. Observa-se que estas bordas são homogêneas, não apresentando bandas de zoneamento químico. Os cristais 4, 5, 6 e 7 foram separados de diques máficos e em particular são homogêneos, e não apresentam qualquer tipo de zoneamento. Já o zircão 11 apresenta núcleo e borda com bandas de zoneamento totalmente difusas, sugerindo que o zircão sofreu forte mobilização química. Cristais que apresentam bandas difusas têm grande probabilidade de resultar em pontos discordantes. Por último os cristais 12, 13 e 14 referem-se a cristais separados de um gabro que não apresentam hábitos prismáticos, e se mostram bastante homogêneos.

No sistema convencional de digestão química completa os cristais das tipologias de 1 a 7 (exceto cristal 5) têm grande probabilidade de fornecer pontos concordantes no diagrama concórdia, enquanto os cristais 5, 8, 9, 10 e 11 provavelmente pontos discordantes. Na imagem CL do cristal 5 observa-se o zircão com uma tonalidade escura e homogênea, sugerindo a presença de altos teores de U. Zircão desta natureza tem grande probabilidade de ser metamítico e, por conseguinte, tem grande possibilidade em perder $\mathrm{Pb}$ radiogênico através de canais abertos.

A baddeleyita apresenta as mesmas características do zircão e, portanto, trata-se de um mineral como excelente marcador de tempo geológico pelo método U-Pb. A Figura 6a mostra um exemplo de variações químicas em termos de $\mathrm{U}$ e $\mathrm{Pb}$ ao longo de um cristal. A Figura $6 \mathrm{~b}$ (em baixo) mostra um mega cristal de baddeleyita encontrado em um kimberlito e (em cima) são baddeleyitas típicas de uma rocha alcalina.

\section{Monazita}

A monazita é um mineral composto essencialmente por fosfatos de Terras Raras leves, $(\mathrm{Ce}, \mathrm{La}) \mathrm{PO}_{4}$. Quando os membros finais do fosfato são compostos por Th $\mathrm{U}$ ou Ca, esse mineral é denominado de brabantita (Ca,Th,U) $\mathrm{PO}_{4}$, (Boswles, 1990; Vlach, 2001). Se for substituído por Y ou ETRP, é denominado de xenotima (Y, ETRP)PO $\mathrm{PO}_{4}$. A Figura 7 mostra algumas tipologias e hábitos típicos de monazita. Na Figura 7a observa-se a monazita com inclusão de zircão, granada e rutilo. As Figuras 7b e 7c são imagens de raios-X que destacam tonalidades mais escuras nas bordas e mais claras na porção central. Tais diferenças de tonalidades indicam que Th e Y se concentram mais na porção central (tonalidade clara) do que nas bordas, enquanto que o Ce se concentra na borda (tonalidade escura) (Kohn e Malloy, 2004). As Figuras 7d, 7e e 7f são imagens de monazita obtidas por elétrons retroespalhados.

\section{PREPARAÇÃO DE AMOSTRA, CONCENTRAÇÃO DE MINERAIS E PROCEDIMENTOS QUÍMICOS}

\section{Preparação de amostra e concentrações de minerais}

A separação e concentração dos minerais, normalmente consistem de britagem, moagem, peneiramento, mesa vibratória, separação eletromagnética, líquidos pesados e por último catação manual. A rotina utilizada no CPGeo é constituída das seguintes etapas:

a. a rocha bruta ( 0,5 a $3 \mathrm{~kg}$ para granitóides e $\sim 20 \mathrm{~kg}$ para rochas máficas) é triturada em um britador de mandíbulas;

b. o material britado é peneirado para separar uma fração de granulometria entre 100 a 250 "mesh", utilizando-se de moinho de disco e uma bateria de peneiras;

c. a fração separada (item b) é submetida a uma mesa vibratória para concentrar minerais pesados tais como zircão, baddeleyita, titanita, monazita, apatita etc.;

d. os minerais magnéticos, tais como, magnetita e pirrotita são removidos com a passagem de ímã de mão;

e. os minerais com diferentes susceptibilidades magnéticas são concentrados no separador magnético tipo Frantz, variando-se a inclinação e a intensidade do campo eletromagnético, por exemplo, 0,5 A com inclinação frontal de $20^{\circ}$ e lateral de $10^{\circ}$ para eliminar a grande maioria dos minerais para-magnéticos, tais como, biotita, piroxênio e anfibólio;

f. a porção menos magnética ou não magnética é passado em líquidos densos, tais como, bromofórmio ( $\mathrm{d}=2,85 \mathrm{~g} /$ $\left.\mathrm{cm}^{3}\right)$ e iodeto de metileno $\left(\mathrm{d}=3,2 \mathrm{~g} / \mathrm{cm}^{3}\right)$ com intuito de separar zircão, baddeleyita e monazita;

g. para eliminar eventuais sulfetos e apatita existentes utiliza-se ácidos $\mathrm{HCl}$ ou $\mathrm{HNO}_{3}$. No caso de apatita também pode ser dissolvida com HF dentro copo de teflon (tipo Savillex ${ }^{\circledR}$ ), mas com temperaturas inferiores a $50^{\circ} \mathrm{C}$ e intervalo de reação entre 3 e 4 h. 
Figura 5. Imagem de catodoluminescência de cristais de zircão de diferentes tipologias formados em diversos ambientes tectônicos. Cristais de 1 a 11 são zircões separados de granitóides; entre 12 a 14 são zircões provenientes de rochas máficas; e o cristal 15 é uma apatita. Os números entre parênteses são idades em Giga anos (Ga).
Figura 6. Imagens de baddeleyitas: a. mostra dois tipos de imagens de BSE das baddeleyitas A e B. Os elementos $\mathrm{U}$ (coluna do meio) e $\mathrm{Pb}$ (coluna da direita) destes cristais, analisados com WDS (pontos circulares), mostram variações sistemáticas na qual a cor com tonalidade mais escura é a região mais enriquecida em $\mathrm{U}$ e $\mathrm{Pb}$, enquanto a cor cinza clara corresponde aos baixos teores destes elementos (French et al., 2004); b. abaixo - representa mega cristal de baddleleyita proveniente de kimberlito (Kerschofer et al., 2000), acima - representa baddeleyita (imagem vista de lupa - luz transmitida) típica de uma rocha alcalina (acervo do (PGeo).

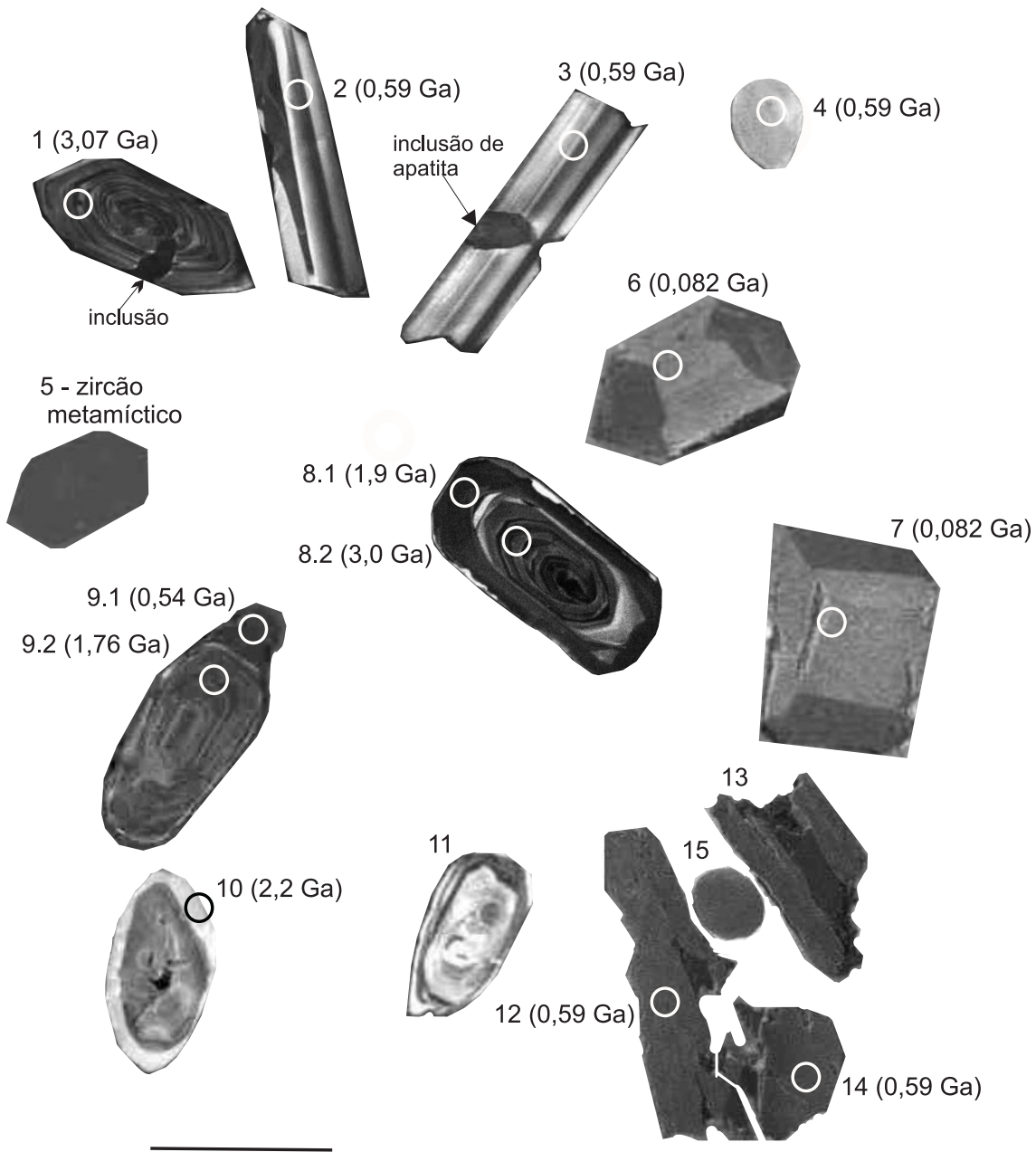

$200 \mu \mathrm{m}$

a

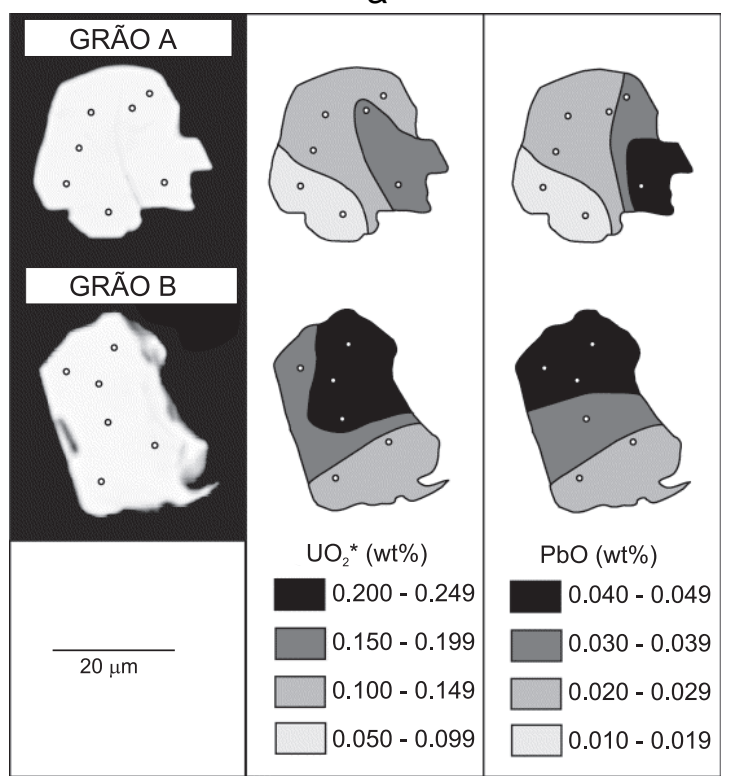

b

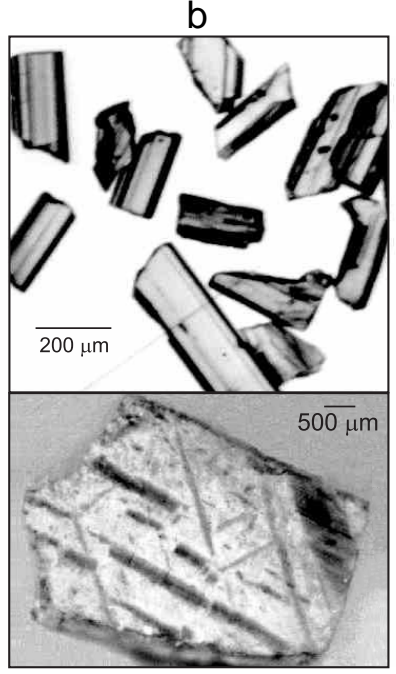


Na etapa final, os minerais concentrados nas etapas anteriores são novamente processados no Frantz mantendo constantes a inclinação frontal de $10^{\circ}$ e a amperagem do campo eletromagnético a $1,5 \mathrm{~A}$ e variando-se a inclinação lateral $\left(10^{\circ}, 8^{\circ}, 6^{\circ} \ldots\right)$, obtendo-se assim as frações de zircão com diferentes suscetibilidades magnéticas. Para mais detalhes, ver também Loios (2004).

\section{Reagentes e ambientes laboratoriais}

a. Reagentes: a água utilizada nos laboratórios químicos, após destilada é bi-destilado em destilador de quartzo e purificada em resina de troca iônica (equipamento MILIQ), resultando em teores de $\mathrm{Pb}$ abaixo de $1 \mathrm{pg} / \mathrm{g}$. Os ácidos $(\mathrm{HCl}$, $\mathrm{HF}, \mathrm{HNO}_{3}$ ) após destilação em sistema de quartzo, são novamente destilados em sistemas de teflon, garrafa x garrafa, em temperatura da ordem de $60^{\circ} \mathrm{C}$. Os teores de $\mathrm{Pb}$ após esse procedimento são inferiores a 2 pg/g. Todos os reagentes, após rigoroso controle de "branco", são armazenados em garrafa de teflon (Nalgene ${ }^{\circledR}$ ) de 1 L. Para diminuir ao máximo a contaminação de $\mathrm{Pb}$ laboratorial, os eluentes utilizados em colunas de troca iônica são colocados em recipientes de teflon (Nalgene ${ }^{\circledR}$ ) (conta-gotas de $30 \mathrm{ml}$ ) sendo adotado o sistema de gotejamento para a recarga dos reagentes nas colunas. Uma gota é estimada em torno de $30 \mu \mathrm{l}$, exceto para $\mathrm{HCl} 6 \mathrm{~N} \mathrm{e}$ $\mathrm{H}_{3} \mathrm{PO}_{4}$ para os quais na tampa do frasco foi adaptado um capilar para escoar microgotas ( $11 \mu \mathrm{l}$ por gota);

b. Ambiente de laboratório químico: é necessário que o ambiente do laboratório, onde são processadas as a amostras de zircão, seja super limpo (ISO 5 e pressão positiva) para que se tenha um "branco" de Pb laboratorial entre 2 a 9 pg. Para isso se utiliza sistema de insuflamento de ar contendo pré-filtros e filtros absolutos, mantendo sempre pressões positivas no ambiente. Nas capelas de insuflamento se utilizam filtros absolutos que permitem um ambiente mais puro.

\section{Digestão química total de zircão e baddeleyita utilizando-se de microbombas de teflon}

Cristais de zircão ou baddeleyita são selecionados em lupa binocular escolhendo-se os cristais de preferência sem inclusões e isentos ou apresentando poucas fraturas. Zircão que apresente tonalidades mais escuras (ou opaco) em luz transmitida deve também ser evitado uma vez que é normalmente metamíctico. $\mathrm{O}$ ataque químico envolve normalmente 1 a 30 cristais, dependendo das dimensões do mineral e da concentração de $\mathrm{Pb}$ presente. Tais condições nem sempre são fáceis de serem avaliadas. Cristais de zircão meso/ paleoproterozóicos ou mesmo arqueanos, com pesos aproximadamente de 2 a $5 \mu \mathrm{g}$, necessitam normalmente de 1 a 5 cristais para a obtenção de idade por método geocronológico
U-Pb. Zircão mais jovem (neoproterozóico e fanerozóico) costuma apresentar pouco $\mathrm{Pb}$ radiogênico, portanto, necessita uma quantidade maior de cristais (neoproterozóicos: 5 a $30 \mu$ g e fanerozóicos: 40 - $80 \mu \mathrm{g}$ ). As quantidades acima citadas são ideais para análises isotópicas no modo estático utilizando-se sistema de detecção Faraday (ver seção de espectrometria de massa). Para análises de mono-cristal, é necessário que "branco" de $\mathrm{Pb}$ do laboratório esteja abaixo de $7 \mathrm{pg}$, pois o cristal de peso entre 1 a $5 \mu \mathrm{g}$ possui $\mathrm{Pb}$ radiogênico da ordem de 100 a $1.000 \mathrm{pg}\left(\mathrm{pg}=10^{-12} \mathrm{~g}\right)$. Existem casos excepcionais onde os teores de $\mathrm{Pb}$ são extremamente baixos (0,1 a $1 \mathrm{ppm})$, neste caso a análise deve ser obrigatoriamente realizada em multigrãos.

Os cristais de zircão, previamente selecionados, são lavados em frasco de teflon (Savillex ${ }^{\circledR}$ ) com $\mathrm{HCl} 6 \mathrm{~N}$ e $\mathrm{HNO}_{3}$ $7 \mathrm{~N}$. Esse procedimento é repetido no mínimo três vezes para remover o máximo possível o $\mathrm{Pb}$ (atual) adsorvido nos cristais (Sproesser et al., 2004). Os cristais lavados são transferidos com uma micropipeta para uma microbomba de teflon (Figura 8a). Adiciona-se a esta $10 \mu \mathrm{l}$ de spike combinado de ${ }^{205} \mathrm{~Pb}$ e ${ }^{235} \mathrm{U}\left({ }^{205} \mathrm{~Pb}=14,683 \mathrm{ppb} ;{ }^{235} \mathrm{U}=1233 \mathrm{ppb}\right)$ e reagentes $\mathrm{HF}+\mathrm{HNO}_{3}$ concentrados $(190 \mu \mathrm{l})$ na proporção 3:1, preenchendo totalmente a microbomba. $\mathrm{O}$ conjunto de microbombas contendo amostras de zircão ou baddeleyita (Figura 8a) é montado dentro de uma cuba de teflon contendo em seu fundo os mesmos reagentes $\left(\mathrm{HF}+\mathrm{HNO}_{3}\right.$; sem spike $)$ utilizados nas microbombas. $\mathrm{O}$ volume total de regentes da cuba deve cobrir o fundo da base da plataforma inferior ( 10 ml) das microbombas. A cuba recebe então uma proteção de aço inoxidável (bomba tipo Parr) para evitar explosões. O conjunto final é colocado dentro de um forno a temperaturas da ordem de $210 \pm 5^{\circ} \mathrm{C}$ e deixando-se nesta condição pelo menos três dias para que ocorra a total digestão química dos cristais.

Após a digestão química na bomba, deve-se evaporar todo o $\mathrm{HF}$ e $\mathrm{HNO}_{3}$ no frasco de teflon (Savillex ${ }^{\circledR}$ ), eliminando-se assim os silicatos. Em seguida adiciona-se na amostra (isento de fluoretos) 1 gota de $\mathrm{H}_{3} \mathrm{PO}_{4}$ e 6 gotas $(180 \mu \mathrm{l}$ ) de $\mathrm{HCl} 6 \mathrm{~N}$ e deixa-se na chapa quente a uma temperatura de 50 - $60^{\circ} \mathrm{C}$ por uma noite. Após este passo, deve-se evaporar totalmente o $\mathrm{HCl}$, deixando apenas microgotas de $\mathrm{H}_{3} \mathrm{PO}_{4}$ contendo amostra de zircão dissolvida e pronta para a etapa da coluna de troca iônica.

\section{As fases de aquecimento e resfriamento das microbombas de teflon}

a. Aquecimento: quando o sistema é aquecido em um forno convencional, o calor externo é transferido inicialmente para a estrutura metálica e, em seguida, para a cuba de teflon (Figura 8b). A seguir, o calor é transferido para a solução ácida da cuba e seus vapores ácidos altamente pressurizados, 
Figura 7. Principais tipos e hábitos de monazita: a. monazita com inclusões de zircão (Zir), granada (Grt) e rutilo (Rut); b e c. imagens de raios $X ; \mathbf{d}, \mathbf{e}, \mathbf{f}$. imagens de monazita obtidas por elétrons retroespalhados.

a

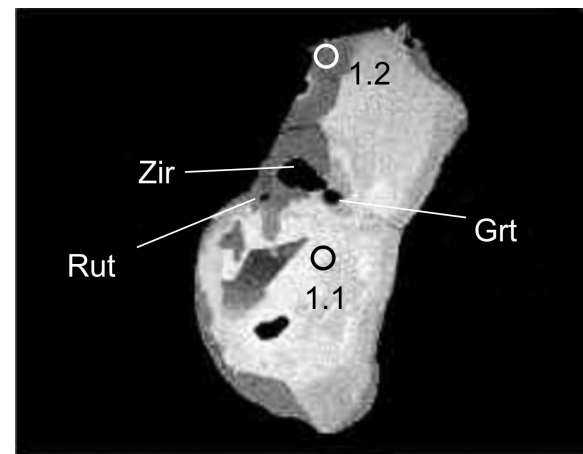

b

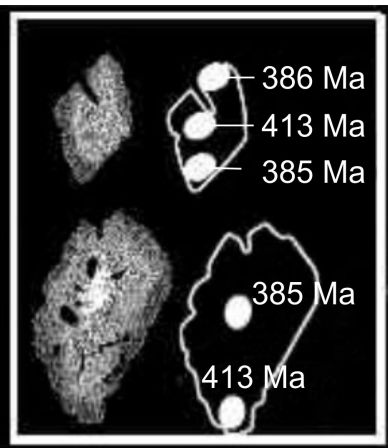

C

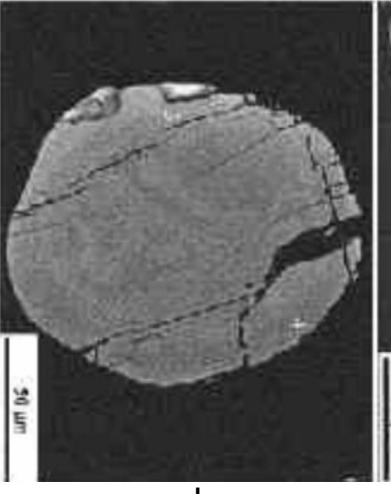

d

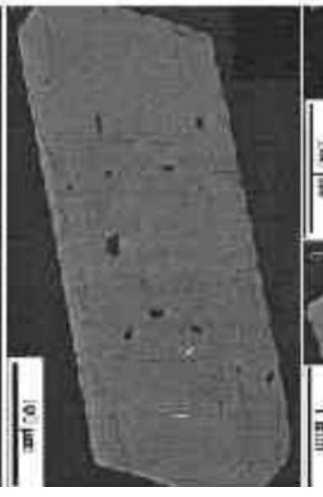

e

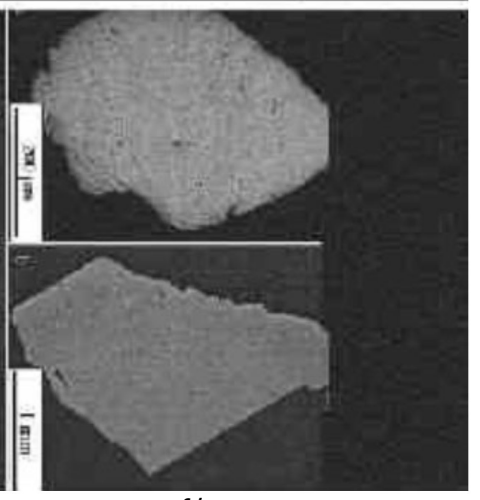

$\mathrm{f} / \mathrm{g}$

a

Figura 8. As microbombas de teflon são montadas em uma estrutura maior (cuba teflon) que, por sua vez, é protegida externamente por uma estrutura metálica de aço inoxidável (figura à esquerda). No desenho esquemático (à direita) encontra-se representado o sistema de circulação dos vapores de ácidos $\left(\mathrm{HF}+\mathrm{HNO}_{3}\right)$ da cuba onde os gases pressurizados colidem de forma intensa e em todas as direções, transportando o calor pelo processo de convecção para as paredes de teflon da microbomba. Por processo de condução - líquido interno da cápsula é então aquecido para realizar a digestão química dos cristais de zircão (detalhes adicionais, ver o texto).

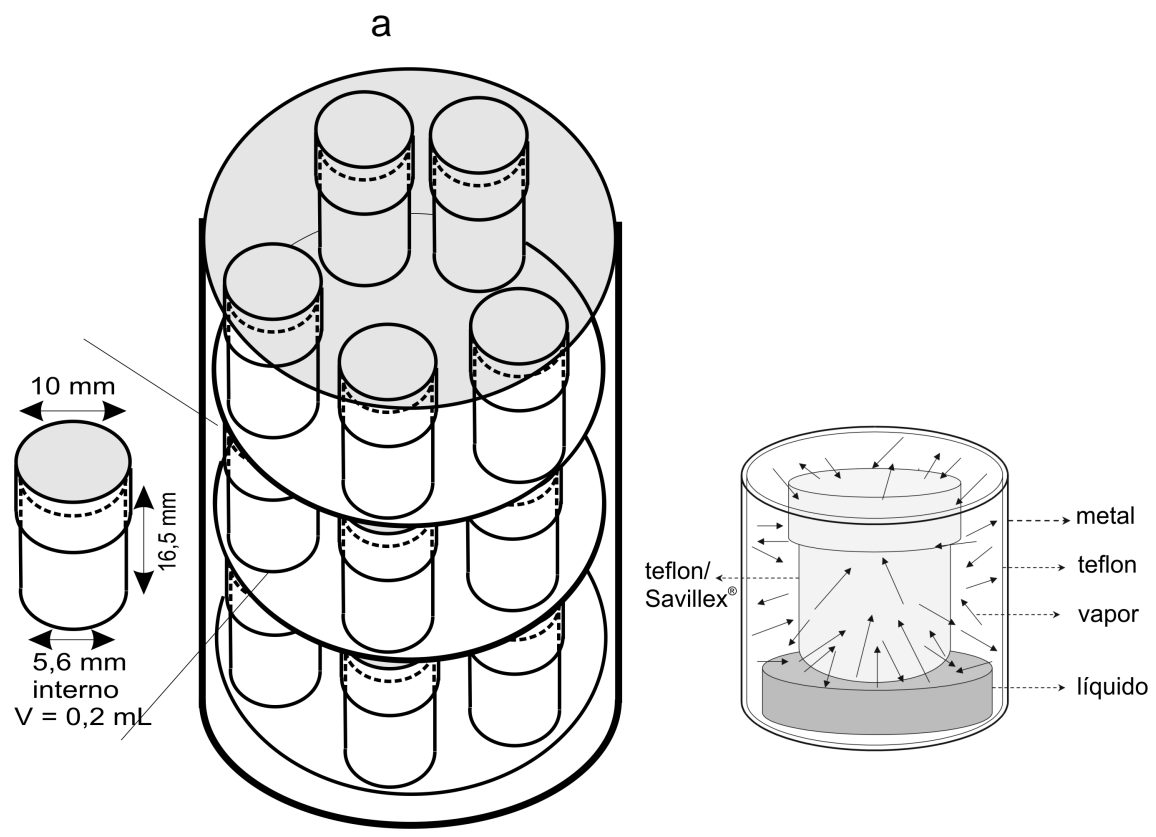


em contacto com as microbombas, aquecem seus regentes internos onde se encontram as amostras. Neste sistema existe inicialmente um gradiente de temperatura que diminui da estrutura metálica para as partes internas das microbombas. A fase inicial, um pouco de reagente da cuba poderá penetrar nas microbombas (se houver espaço), embora as mesmas estejam protegidas por um tampa, uma vez que a pressão interna nas microbombas é ainda menor;

b. Resfriamento: quando o forno é desligado, há um gradiente de temperatura que diminui da microbomba para a estrutura metálica externa. Nesta etapa pode ocorrer um pequeno vazamento do ácido de microbomba para a cuba contaminando os reagentes da mesma. Portanto, o sistema nunca deve ser resfriado e reaquecido novamente, pois as microbombas poderão sofrer contaminação dos reagentes da cuba durante a fase inicial de reaquecimento.

\section{Digestão parcial - técnica de lixiviamento}

A técnica de lixiviamento através de digestão química controlada (TLDQC) permite a análise de zonas de bordas e núcleos de alguns tipos de zircão. Para isto, é essencial que tenha um estudo prévio das imagens de catodoluminescência (CL) ou de elétron retroespalhado. Os cristais de zircão selecionados, para serem analisados por esta técnica (TLDQC), devem ter mesmo tipo de hábito ou tipologia aos daqueles estudados previamente com auxílio de CL (a exemplo do cristal 10, Figura 5; ver também Figuras 17c e 17d).

Os cristais de zircão selecionados são colocados dentro de frasco de Savillex ${ }^{\circledR}$ para receber lavagem com $\mathrm{HNO}_{3}$ para remoção do $\mathrm{Pb}$ atual impregnado nos grãos. Os cristais prélavados são então atacados em mini-copos de teflon (volume de $3 \mathrm{ml}$ e tampa de rosca fina) utilizando ácido HF concentrado com volume em torno de $90 \mu \mathrm{l}$ para 1 a 10 cristais de zircão. Para efetuar a digestão química parcial controlada utiliza-se um forno de microondas comercial, operado em uma capela de exaustão, para remoção de escape eventual de vapor ácido. O controle de temperatura, bem como o tempo de reação química são feitos variando-se a potência e o relógio do forno. A temperatura máxima é de $150^{\circ} \mathrm{C}$ e o tempo de reação química, é feito em 4 ciclos de 90 min deixando 10 min de descanso entre cada ciclo, para não danificar o forno.

A solução ácida contendo elementos químicos, entre os quais $\mathrm{Pb}$ e $\mathrm{U}$, proveniente do lixiviado, inicialmente, da borda do zircão (para cristais não fraturados e não metamícticos) deve ser cuidadosamente separada dos cristais remanescentes usando uma micropipeta e transferindo somente o líquido para um outro novo frasco de teflon (Savillex ${ }^{\circledR}$ ). Em seguida adiciona-se $10 \mu \mathrm{l}$ de spike combinado ${ }^{205} \mathrm{~Pb}$ ${ }^{235} \mathrm{U}$ e $1 \mu \mathrm{l}$ de $\mathrm{H}_{3} \mathrm{PO}_{4} 0.1 \mathrm{~N}$ sobre ao novo copo e a seguir é levado a uma chapa quente $\left(\sim 70^{\circ} \mathrm{C}\right)$ para evaporar totalmente o $\mathrm{HF}$, deixando apenas uma pequena microgota de $\mathrm{H}_{3} \mathrm{PO}_{4}$ contendo material lixiviado e spike ${ }^{205} \mathrm{~Pb}$. A seguir, adicionase $180 \mu \mathrm{l}$ de $\mathrm{HCl} 6 \mathrm{~N}$ e deixa-se por uma noite a $60^{\circ} \mathrm{C}$. A próxima etapa segue o procedimento de eluição em microcolunas de troca aniônica, com objetivo de concentrar apenas os elementos $\mathrm{Pb}$ e $\mathrm{U}$.

O procedimento acima descrito deve ser realizado pelo menos 2 vezes, recarregando novamente com $90 \mu$ l de HF o frasco de teflon (Savillex ${ }^{\circledR}$ ) contendo os cristais de zircão parcialmente lixiviados da etapa anterior. A etapa final consiste no ataque químico do zircão residual presente no copo, após as etapas de lixiviação é realizado nos mesmos moldes de digestão química em microbombas, conforme descrição anterior.

\section{Digestão química de monazita}

A monazita é um mineral normalmente com alto conteúdo de $\mathrm{U}$ e $\mathrm{Pb}$, geralmente com teores de $\mathrm{Pb}$ entre 500 a 20.000 ppm. Devido à alta concentração destes dois elementos químicos, coloca-se apenas um cristal com massa ao redor de $1 \mathrm{a}$ $7 \mu \mathrm{g}$. O cristal deve ser lavado com $\mathrm{HNO}_{3}(\sim 6 \mathrm{~N})$ e $\mathrm{HCl}(6 \mathrm{~N})$ pelo menos três vezes para remoção do $\mathrm{Pb}$ superficial. Sobre o cristal contendo a monazita em frasco de teflon (Savillex ${ }^{\circledR}$ ), coloca-se ácido sulfúrico concentrado com uma quantidade suficiente para cobrir o grão ( 30 a $60 \mu \mathrm{l})$. A digestão química é feita em uma chapa quente com temperatura ao redor de $150^{\circ} \mathrm{C}$ (temperatura próxima da fusão do teflon) deixando nesta condição no mínimo durante $24 \mathrm{~h}$. Caso se tenha muito $\mathrm{Pb}$ (>>5.000 pg), deve-se trabalhar em alíquota de tal forma que a fração ideal tenha algo entre 1.000 a 7.000 pg. Tal quantidade é ideal para adicionar $10 \mu \mathrm{l}$ de spike combinado de ${ }^{205} \mathrm{~Pb}(147 \mathrm{pg})$ - ${ }^{235} \mathrm{U}$ (12.336 pg).

\section{Digestão química de titanita}

Para a datação de cristais de titanita deve-se selecionar em lupa, grãos isentos de fraturas e inclusões e preferencialmente com aspectos mais escuros por estes possuírem maior quantidade de urânio. A digestão química deve ser realizada com cerca de $0,5 \mathrm{mg}$ (aproximadamente 80 cristais) de titanita. Após a pesagem, os cristais são lavados com $\mathrm{HNO}_{3}(6 \mathrm{~N})$ para retirada de matéria orgânica. $O$ ataque químico é efetuado de modo similar ao realizado para o zircão (descrito anteriormente), utilizando-se de bomba de teflon de capacidade média.

\section{Procedimentos de concentração de $\mathrm{Pb}$ e $\mathrm{U}$ em microcolunas de troca aniônica (zircão, baddeleyita, monazita e titanita)}

Os procedimentos de concentração de $\mathrm{Pb}$ e U contidos no material resultante do ataque químico, seja ele obtido por processos de digestão química parcial (lixiviamento), 
ou por digestão total, são realizados em microcolunas de troca aniônica previamente calibrada.

As microcolunas com diâmetro interno de 2,5 mm e altura de 14 mm, onde são preenchidos com $70 \mu \mathrm{l}$ de resina aniônica do tipo Eichron. No topo da coluna há um reservatório de $700 \mu \mathrm{l}$ para colocar os eluentes (Figura 9a). Tais procedimentos devem ser precisos, uma vez que as colunas foram calibradas para $\mathrm{U}$ e $\mathrm{Pb}$ nas condições apresentadas (Anexo 2). A Figura 9b mostra a calibração de uma microcoluna utilizada no CPGeo-IGc/USP. O procedimento de eluição encontra-se no Anexo 2.

Na calibração das microcolunas, além da determinação da faixa ideal de coleta do $\mathrm{Pb}$ e U, cuidados devem ser tomados com as alterações de compactação da resina, variações das normalidades e dos volumes dos eluentes descartados/ coletados e mudanças de temperatura (inverno/verão) que podem modificar as faixas das coletas. Na Figura 10 observase os dados obtidos para eluição do padrão NBS 983, cujo conteúdo de $\mathrm{Pb}$ total dos reagentes foi estimado em $5 \mathrm{pg}$. $\mathrm{O}$ valor da razão ${ }^{207} \mathrm{~Pb} /{ }^{206} \mathrm{~Pb}$ do NBS 983 é 0,07118 (sem a cor- reção do fracionamento da medida isotópica) e a razão ${ }^{207} \mathrm{~Pb} /{ }^{206} \mathrm{~Pb}$ do $\mathrm{Pb}$ do laboratório possui valor médio de 0,917. Pequenas variações da faixa de coleta para teores elevados de $\mathrm{Pb}$ (6.000 a 3.000 pg) não afetam o valor da razão ${ }^{207} \mathrm{~Pb} /{ }^{206} \mathrm{~Pb}$. No entanto, quando o teor de $\mathrm{Pb}$ do padrão é abaixo de 1.000 pg, em decorrência do deslocamento da faixa de coleta, a razão ${ }^{207} \mathrm{~Pb} /{ }^{206} \mathrm{~Pb}$ modifica-se de forma significativa (Figura 10) devido ao $\mathrm{Pb}$ comum presente nos reagentes. A mudança no valor da razão ${ }^{207} \mathrm{~Pb} /{ }^{206} \mathrm{~Pb}$ decorre em função de dois fatores:

a. diminuição da quantidade de $\mathrm{Pb}$ do padrão coletada;

b. presença constante de $\mathrm{Pb}$ nos reagentes utilizados na eluição em toda a faixa de coleta (exceto o $\mathrm{Pb}$ presente nos reagentes utilizados no ataque químico, que diminuem de forma proporcional em relação à amostra).

Se o padrão for coletado fora da faixa da calibração e tenha apenas 120 pg e considerando um branco de $\mathrm{Pb}$ da ordem de 5 pg (somente aos reagentes utilizados na coluna

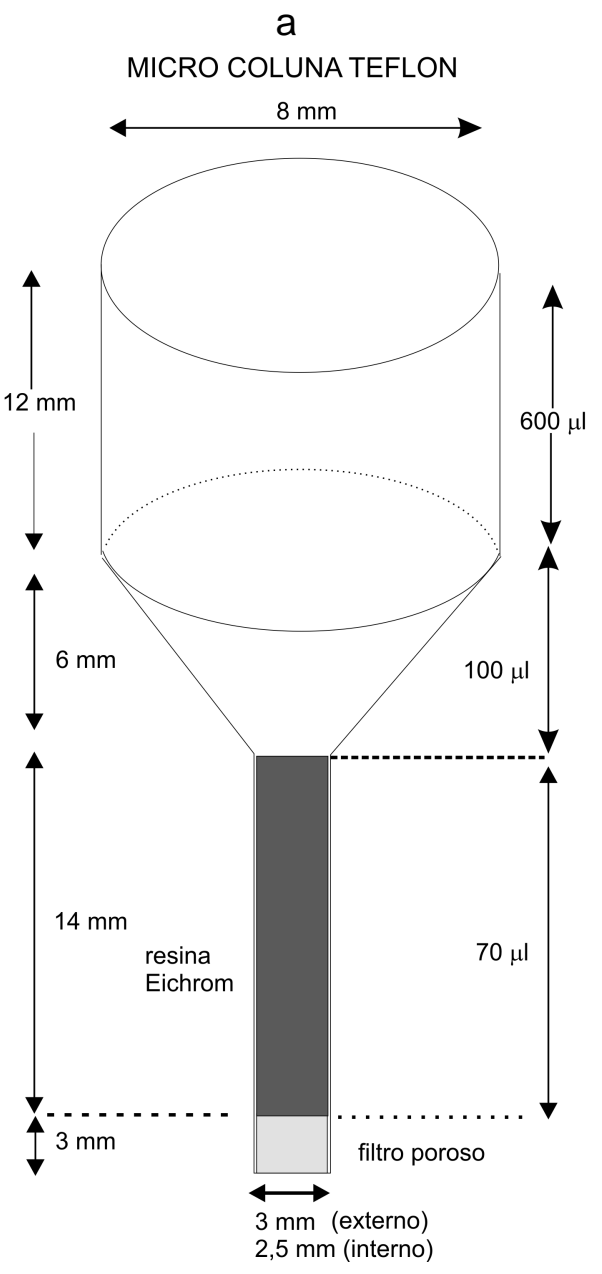

b

DISTRIBUIÇÃO DE Pb EM ELUIÇÃO EM COLUNA DE TROCA IÔNICA (AMOSTRA / SPIKE)

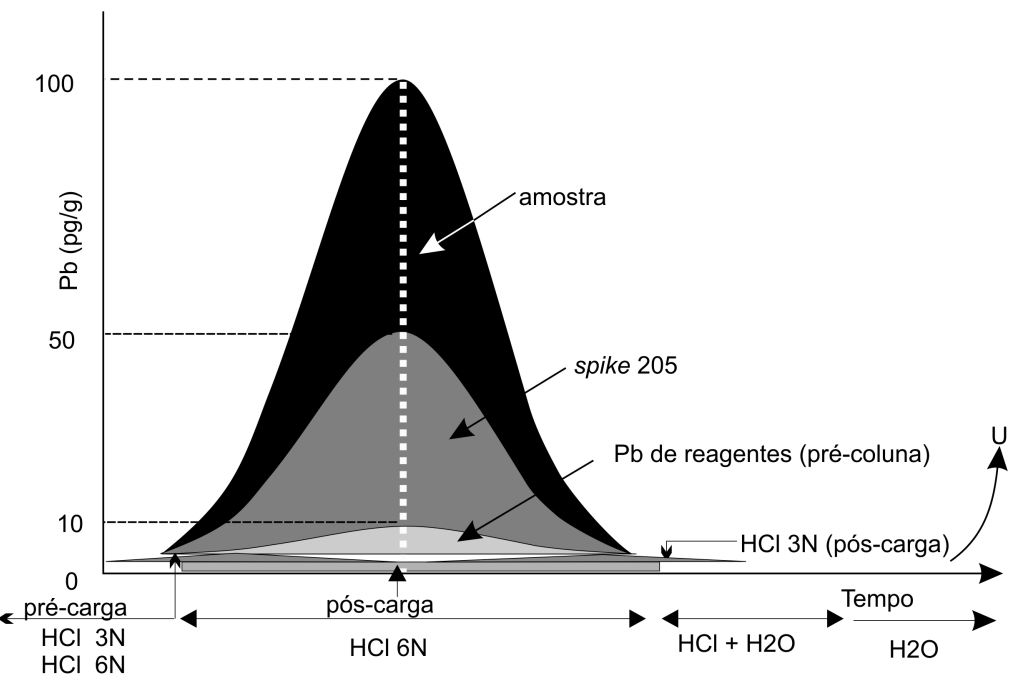

Figura 9. Desenho esquemático da micro-coluna (lado esquerdo) e faixa de calibração para elemento $\mathrm{Pb}$ (lado direito). No Anexo 2 encontram-se os detalhes da calibração. 
de troca aniônica), para qualquer que seja a faixa coletada, portanto, teremos $4 \%$ de contaminação de $\mathrm{Pb}$ comum $\left({ }^{207} \mathrm{~Pb} /{ }^{206} \mathrm{~Pb}=0,917\right.$; abundância de ${ }^{206} \mathrm{~Pb}=24,1 \%$ e de $\left.{ }^{207} \mathrm{~Pb}=22,1 \%\right)$. Este modificará de forma significativa a razão do padrão $\left({ }^{207} \mathrm{~Pb} /{ }^{206} \mathrm{~Pb}=0,0712\right.$; abundância de ${ }^{206} \mathrm{~Pb}=92,15 \%$ e $\left.{ }^{207} \mathrm{~Pb}=6,56 \%\right)$. A razão isotópica ${ }^{207} \mathrm{~Pb} /{ }^{206} \mathrm{~Pb}$ da mistura deverá levar em conta as quantidades e abundâncias dos isótopos envolvidos (Figura 10). Em caso de amostra, quando a influência do $\mathrm{Pb}$ contaminante torna-se significativa, necessita-se de correções do branco total (ver PBDAT no Anexo 1), que nem sempre resultam em valores precisos, devido às flutuações dos teores de $\mathrm{Pb}$ laboratorial.

\section{Descontaminação dos materiais}

Descontaminação das bombas: inicialmente os materiais adsorvidos nas paredes das microbombas são removidos grosseiramente com uso de cotonetes e enxaguados com $\mathrm{H}_{2} \mathrm{O}$. Os materiais são então mergulhados em $\mathrm{HNO}_{3} \mathrm{e}$ $\mathrm{HCl}$ concentrados e fervidos a uma temperatura da ordem de 50 a $60^{\circ} \mathrm{C}$. Por último, a limpeza é realizada nos mesmos moldes do ataque químico (dentro do forno a $200^{\circ} \mathrm{C}$ ).

Descontaminação de material: a limpeza de frasco de teflon (Savillex®) é feita com $\mathrm{HNO}_{3} 6 \mathrm{~N} \mathrm{e} \mathrm{HCl} 6 \mathrm{~N}$ utilizando-se o forno de microondas com uma potência média durante 30 min. O aquecimento acompanhado de vibração das moléculas aumenta a eficiência de descontaminação dos materiais.

DISTRIBUIC̃̃O DE Pb EM ELUIĈ̃O EM COLUNA DE TROCA IÔNICA (NBS 983)

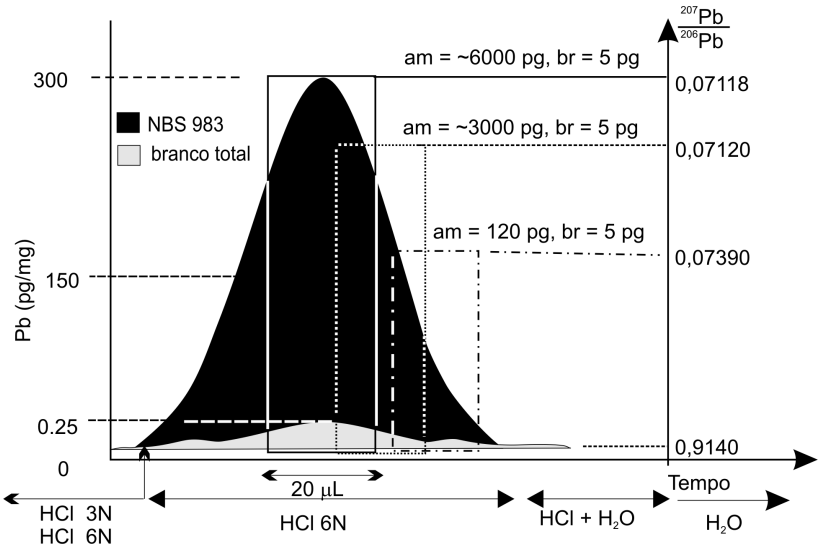

Figura 10. Efeitos de deslocamentos das faixas de coletas em relação zona central de calibração. A razão ${ }^{207} \mathrm{~Pb} /{ }^{206} \mathrm{~Pb}$ $(0,07118)$ do NBS 983 irá modificar gradativamente à medida que se afasta da faixa central do histograma devido à contribuição do $\mathrm{Pb}$ comum $(0,914)$. Legenda: $\mathbf{a m}=$ amostra, $\mathbf{b r}=$ branco, $\mathbf{p g}=$ picogramas.
Branco total: obter valor de branco total abaixo de $4 \mathrm{pg}$ é uma tarefa muito difícil em um ambiente super poluído como a cidade de São Paulo. O branco total no laboratório químico de U-Pb do CPGeo tem variado entre 3 a 10 pg de $\mathrm{Pb}$ (de 2000 até o presente dia).

\section{LABORATÓRIO DE ESPECTROMETRIA DE MASSA}

\section{Deposição de amostra em filamento}

Ao $\mathrm{U}$ e $\mathrm{Pb}$ concentrados na coluna de troca iônica são adicionados 1 a $2 \mu$ l de solução de silicagel (concentrada) + ácido fosfórico para a dissolução destes elementos e, em seguida, são coletadas com micropipeta para serem depositados sobre o filamento de Re previamente descontaminado em altas temperaturas $\left(>1.600^{\circ} \mathrm{C}\right)$ em uma câmara de alto vácuo. O aquecimento, para remover a água e o ácido fosfórico depositado sobre o filamento (Figura 11a), é realizado de forma lenta (1 a 2 min), a uma corrente inicial de 0,5 A para evaporar a água e, em seguida, a $1 \mathrm{~A}$, permanecendo nesta corrente durante 0,5 a 1 min. Para evaporar o ácido fosfórico eleva-se a corrente acima de 1,9 A (em função da espessura do filamento) e espera-se até que não saia mais fumaça de cor branca (menos que $60 \mathrm{~s}$ ). $\mathrm{O}$ aquecimento final é realizado deixando-se o filamento ao rubro $\left(800^{\circ} \mathrm{C}\right)$ por 3 a 5 s. Não efetuar super aquecimentos, pois, a amostra sobre o filamento perderá a aderência e poderá cair. A Figura 11b mostra um filamento na forma de canoa onde é colocado um cristal de zircão para ser analisado pelo método de evaporação de $\mathrm{Pb}$ por aquecimento por passo.

\section{Medidas isotópicas - TIMS}

Os principais espectrômetros de massa de ionização térmica existentes no CPGeo até a presente data são VG354 Multicoletor, VG 354 monocoletor, Finnigan MAT 262 e Finnigan MAT TRITON. Os princípios de funcionamento dos diversos tipos de espectrômetros de massas encontram-se descritos em Sato e Kawashita (2002). Novos equipamentos estão sendo implementados no CPGeo (no presente momento, em fase de instalação), tais como, NEPTUNE (ICP-MS) e SHRIMP (sonda iônica). Além deste parque de instrumentação, o CPGeo possui três espectrômetros de fonte gasosa (MAP, Nuclide e Delta Plus).

\section{Análises isotópicas de $\mathrm{Pb}$}

As análises isotópicas de $\mathrm{Pb}$ proveniente dos concentrados de zircão, baddelleyita, monazita etc. são feitas nos espectrômetros de massa Finnigan MAT 262 e TRITON multicoletor (8 copos de Faraday e um sistema de multiplicador de elétrons acoplado a um contador de pulsos, conhecido 
a

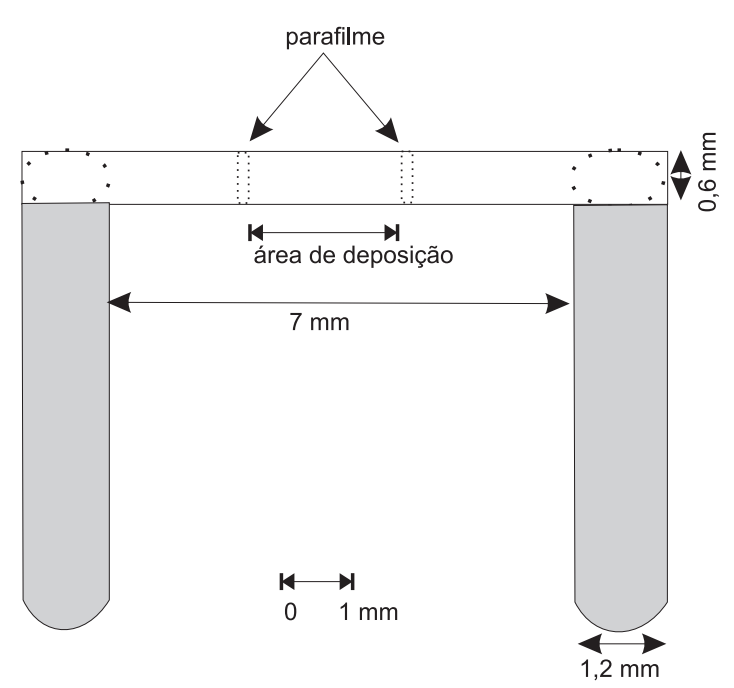

b

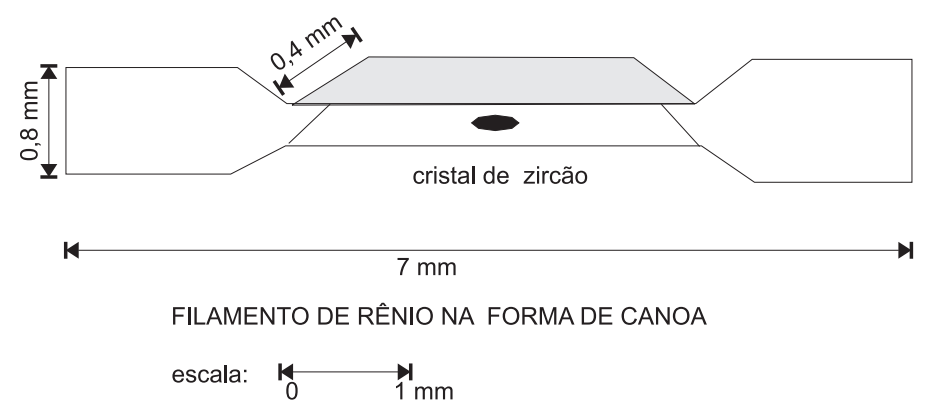

Figura 11. a. Desenho esquemático do filamento montado em um suporte. O filete de parafilme é fixado sobre o filamento aquecendo-se a 1,2A. A área de deposição de amostra fica limitada entre as barreiras de parafilme que impedem que solução escoe na direção do poste (suporte de filamento). A solução de amostra deve ser evaporada aquecendo em quatro passos: 1. 0,7A ( $\sim 1 \mathrm{~min}$ - evaporar água sem borbulhar); 2. elevar a corrente para 1 a 1,2A ( 1 min) para evaporar totalmente a água; 3. elevar a corrente a 1,7 - 1,9A (evaporar totalmente o parafilme e $\mathrm{H}_{3} \mathrm{PO}_{4}$ ); 4. aquecer o filamento ao rubro (corrente $>1,9 \mathrm{~A}-\sim 800^{\circ} \mathrm{C}$ ) durante $10 \mathrm{~s}$ (cuidado para não entrar em combustão). b. Filamento na forma de canoa onde é prensado um cristal de zircão para efetuar técnica de evaporação de $\mathrm{Pb}$ por aquecimento por passo.

como contador de íons). As análises isotópicas no modo estático requerem uma calibração prévia dos coletores, de tal modo que todos os isótopos de $\mathrm{Pb}$ (204, 205, 206, 207 e 208, nos quais 205 é o spike) entrem com a máxima transmissão nos seus respectivos detectores. Após este ajuste, é necessário calibrar os ganhos dos amplificadores, relativo ao amplificador axial, utilizando-se uma fonte de corrente altamente estável. Também é necessário determinar o fator de ganho entre o contador de íons e o Faraday, pois, normalmente utiliza-se o contador de íons para a massa ${ }^{204} \mathrm{~Pb}$ e para os demais isótopos de $\mathrm{Pb}$ (205, 206, 207 e 208) em copo de Faraday. Quando o teor de Pb é extremamente baixo ( $<200$ pg) utilizase um único coletor (contador de íons - CI) e os isótopos são medidos mudando-se a intensidade de campo magnético para que uma determinada massa de $\mathrm{Pb}$ entre no detector $\mathrm{CI}$. Para cada massa há uma determinada intensidade do campo magnético correspondente, que deve estar previamente calibrada. Este procedimento de medidas de isótopos na forma seqüencial é conhecido como "peak jump".

Para certificar-se da precisão, exatidão e fracionamento das medidas isotópicas são realizados várias medidas iniciais com NBS 983. A quantidade de Pb de NBS 983 depositado deve ser ao redor de $2 \eta \mathrm{g}$ ou 2.000 pg, que é equivalente a quantidade de $\mathrm{Pb}$ existente em aproximadamente 10 cristais de zircão (considerando-se que um zircão tem em média ao redor de 200 pg de $\mathrm{Pb}$ radiogênico). A calibração de ga- nhos dos amplificadores entre os detectores CI e Faraday deve ser feita diariamente, pois o CI varia suas características de forma sistemática com o uso. Informações adicionais sobre a espectrometria podem ser obtidas no manual interno de Sato (2007) e Sato e Kawashita (2002).

A emissão de $\mathrm{Pb}$ inicia-se ao redor de $800^{\circ} \mathrm{C}$, mas nesta condição inicial existe uma grande quantidade de elementos interferentes, tais como materiais orgânicos, Tl, Hg etc. A interferência é reduzida para a temperatura acima de $1.250^{\circ} \mathrm{C}$, após $10 \mathrm{~min}$ de aquecimento. Condições estáveis e praticamente sem interferências de elementos indesejáveis nas análises são adquiridas entre 1.250 a $1.350^{\circ} \mathrm{C}$. Os espectros hipotéticos das composições isotópicas de $\mathrm{Pb}$ comum, zircão e monazita podem ser vistas na Figura 12.

\section{Análises das razões isotópicas de $U$}

Pelo fato do U ser facilmente oxidado em ambientes de pressões elevadas (pressão atmosférica a $10^{-5} \mathrm{mbar}$ ) sob temperaturas acima de $800^{\circ} \mathrm{C}$, os isótopos de U são medidos na forma de dióxido de urânio $\left(\mathrm{UO}_{2}\right)^{+}$. Portanto, para obter a razão isotópica ${ }^{235} \mathrm{U} /{ }^{238} \mathrm{U}$ são medidas as massas 267 e 270 . A ionização de $\mathrm{U}$ inicia-se a temperaturas superiores a $1.200^{\circ} \mathrm{C}$, sendo normalmente analisados a temperaturas entre 1.300 a $1.450^{\circ} \mathrm{C}$. Tais condições permitem um aumento na intensidade de emissão do feixe de íons e a obtenção de medidas isotópicas 
mais precisas. O spike adicionado (no início do ataque químico) permite o cálculo da concentração de ${ }^{235} U$. As análises isotópicas são normalmente realizadas no modo estático utilizando-se os coletores Faraday, porém se a emissão de feixe de íons for muito baixa, utiliza-se o contador de íons.

\section{Fator de discriminação de massa}

Para análises isotópicas precisas de $\mathrm{Pb}$, além da calibração dos ganhos dos amplificadores, é necessária também a verificação do fator de fracionamento ( $F$ ou $\delta$ ) ou discriminação de massa por unidade de massa atômica. A Figura 13 contém um diagrama esquemático que mostra as variações das razões isotópicas em função do tempo (Figura 13, topo) e a variação do valor de discriminação por uni-

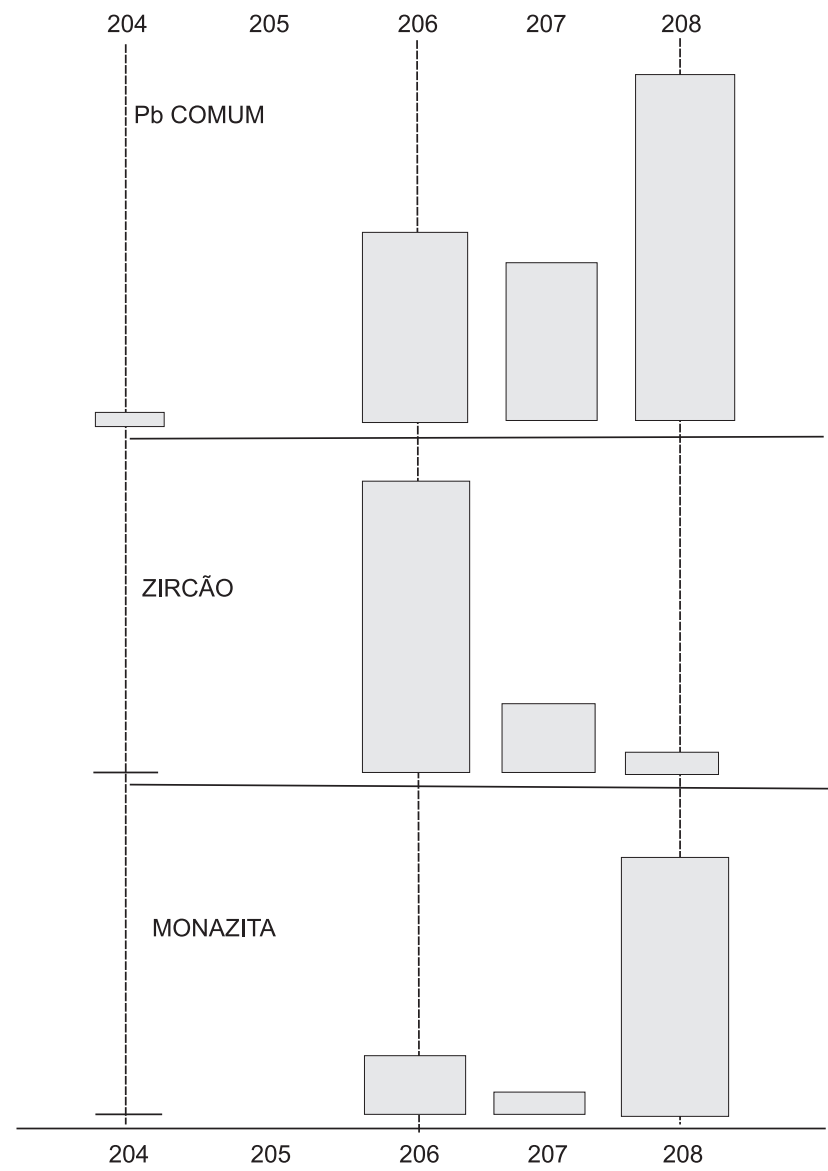

Figura 12. Espectros de $\mathrm{Pb}$ ( $\mathrm{Pb}$ comum, zircão e monazita) sem spike. Dados das razões isotópicas do NBS 983 obtidos no CPGeo após a correção de fracionamento são: ${ }^{204} \mathrm{~Pb} /{ }^{206} \mathrm{~Pb}=$ 0,$000369 ;{ }^{207} \mathrm{~Pb} /{ }^{206} \mathrm{~Pb}=0,071212,{ }^{208} \mathrm{~Pb} /{ }^{206} \mathrm{~Pb}=0,013617$. $\mathrm{A}$ monazita normalmente é concentrada em ${ }^{208} \mathrm{~Pb}$ (entre 70 a $85 \%$ em relação ao $\mathrm{Pb}$ total), pois é mais enriquecido em Th do que $\mathrm{U}$, e pode ser representada quimicamente como $(\mathrm{Ce}, \mathrm{La}, \mathrm{Th}) \mathrm{PO}_{4}$. dade de massa, também em função do tempo (Figura 13,

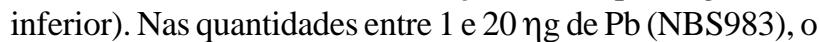
valor médio de $\mathrm{F}$ para o espectrômetro de massa Finnigan MAT 262 do CPGeo varia entre 0,0010 e 0,00075 (em média igual a 0,0085) por unidade de massa atômica (u.m.a.), e para o TRITON é 0,0011 u.m.a.

Dados relativos às razões isotópicas do padrão NBS 983, sem a correção da discriminação de massa, encontramse na Figura 14. Os erros analíticos e a variação do fator de discriminação de massa aumentam em função da diminuição da quantidade de amostra. Isto é, quanto menor a quantidade de amostra depositada, menor será a intensidade de feixe de íons produzidos no filamento estando, por conseguinte, mais suscetível a maiores flutuações das medidas isotópicas. Pequena quantidade de amostra no filamento irá diminuir o tempo útil quanto a sua produção de feixes de íons com intensidades altas e constantes. Tal fato irá acarretar uma variação maior no fator de discriminação ao longo do tempo analítico quando comparado com resultados de análise de grande quantidade de material depositado.

Outro fator que altera as razões é o fator de transmissão dos feixes de íons, característico de cada equipamento, ou seja, nem sempre $100 \%$ dos íons entram em um determinado

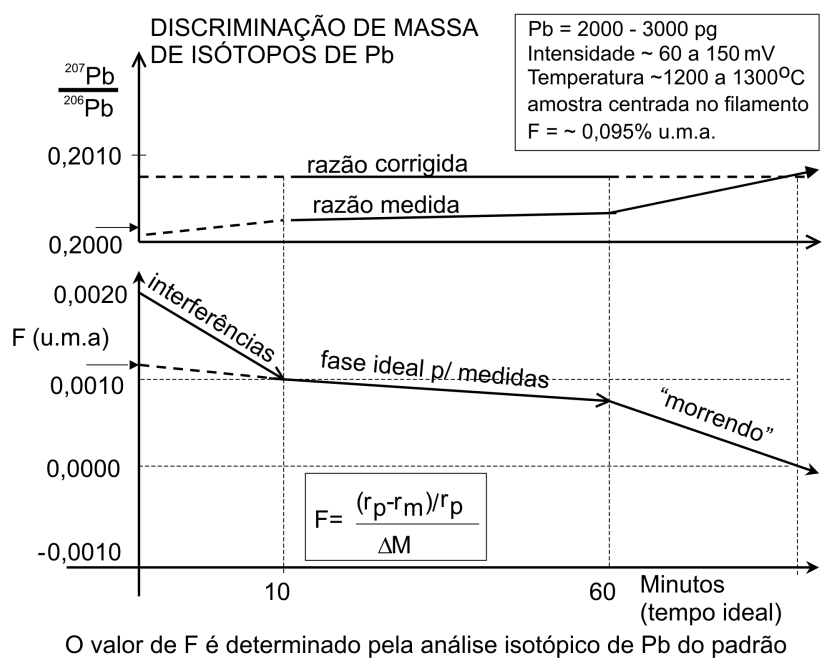

Figura 13. O valor do fator de fracionamento $F$ é determinado a partir da simulação do padrão cuja razão é bem conhecida. Na fase inicial ocorrem problemas de interferências principalmente nas amostras. $\mathrm{O}$ valor de $\mathrm{F}$ varia em função da quantidade de amostra analisada, área depositada no filamento, temperatura de ionização e tempo de análise. Portanto, o valor do fator de discriminação de massa deve ser um valor médio de várias determinações analisadas em dias e meses distintos. $O$ intercepto inicial de $F$ para o padrão (linha tracejada) é constante para determinada quantidade de amostra conhecida, em um determinado equipamento. 


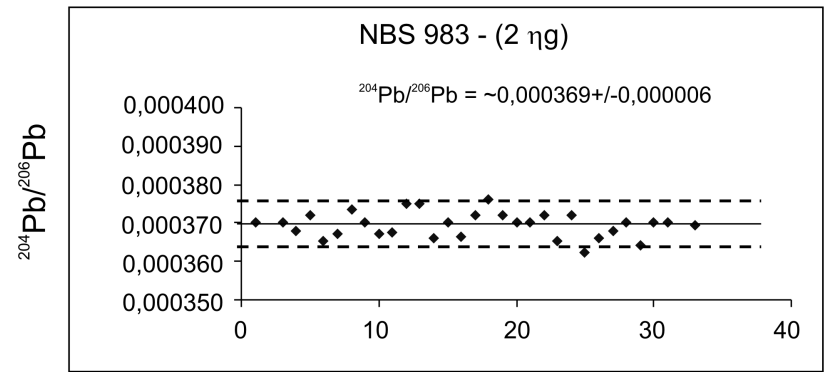

pontos de análises (ano 2004 - 2006)

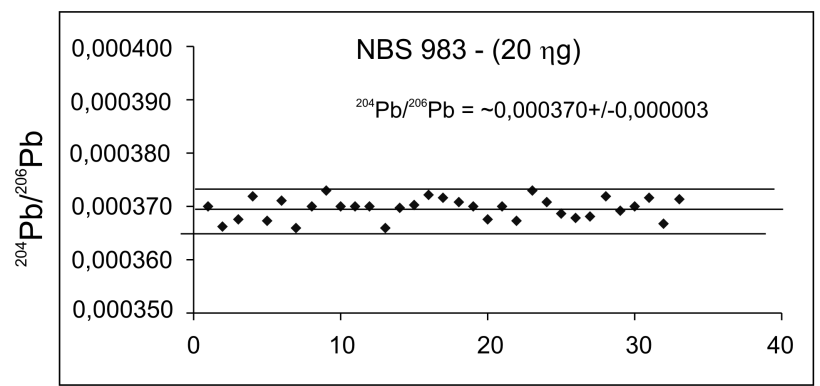

pontos de análises (ano 2004 - 2006)

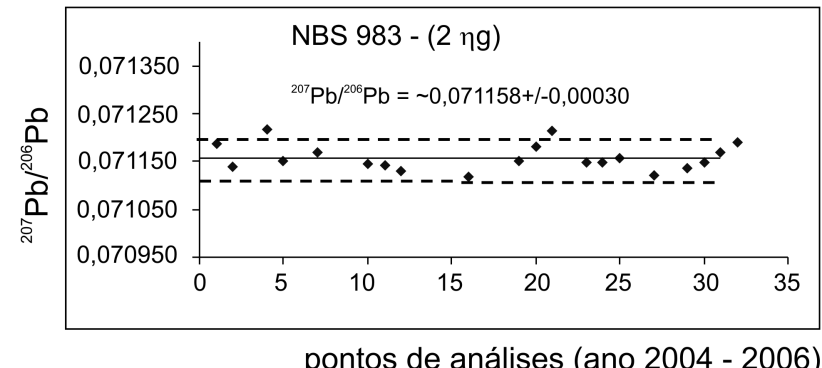

pontos de análises (ano 2004 - 2006)

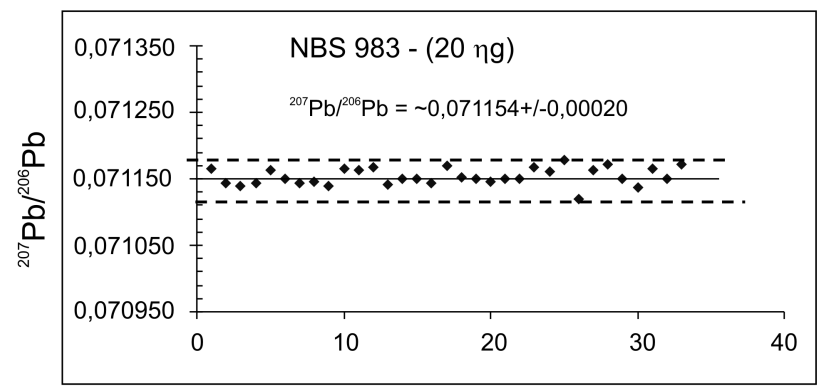

pontos de análises (ano 2004 - 2006)

Figura 14. Razões isotópicas do padrão de Pb NBS983 obtidos no MAT 262. Para as medidas isotópicas do Pb (2 クg) foram utilizados os detectores de contador de íons para a massa 204 e o demais isótopos em copos de Faraday. Para as medidas isotópicas de $\mathrm{Pb}$ com quantidade de $20 \mathrm{\eta g}$ foram todos analisados em copos de Faraday e no modo estático. As razões ${ }^{204} \mathrm{~Pb} /{ }^{206} \mathrm{~Pb}$ e ${ }^{207} \mathrm{~Pb} /{ }^{206} \mathrm{~Pb}$ não estão corrigidas em relação aos fracionamentos de massa. O fator de

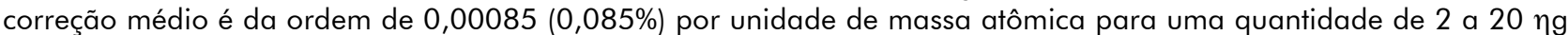
de padrão analisado.

coletor. A correção denominada "bias" deve ser utilizada para corrigir, caso haja problemas de transmissão de feixe de íons. O procedimento para correção de “bias” pode ser feito utilizando os padrões NBS 983, 982 e 981. Caso haja um desvio sistemático nos valores obtidos, pode-se calcular facilmente o fator de correção. Outra forma de determinar o fator de transmissão é colocar um determinado sinal de feixe de íons estáveis em todos os detectores na forma de "peak jump” e verificar se existem diferenças de transmissão.

As razões isotópicas de $\mathrm{Pb}$ do padrão NBS 983 obtidos no CPGeo (MAT 262 anos base 2004 - 2006 e TRITON ano base 2008) em 1.000 a 20.000 pg analisados após as correções de fracionamento de massas foram:

\begin{tabular}{cc}
\hline MAT 262 & TRITON \\
\hline${ }^{207} \mathrm{~Pb} /{ }^{206} \mathrm{~Pb}=0,071211 \pm 0,000025$ & $0,071219 \pm 0,000015$ \\
${ }^{208} \mathrm{~Pb} /{ }^{206} \mathrm{~Pb}=0,013617 \pm 0,00008$ & $0,013613 \pm 0,000006$ \\
${ }^{204} \mathrm{~Pb} /{ }^{206} \mathrm{~Pb}=0,000369 \pm 0,000004$ & $0,000368 \pm 0,000002$ \\
\hline
\end{tabular}

\section{Correções de fracionamento, de "branco" de laboratório e de $\mathrm{Pb}$ inicial}

Os resultados das razões isotópicas de amostras, além da correção de fracionamento de massa, devem ainda passar por correções relativas ao do branco de $\mathrm{Pb}$, do laboratório e do $\mathrm{Pb}$ inicial. $\mathrm{O} \mathrm{Pb}$ inicial contido no reticulo do zircão, normalmente incorporado no momento de sua cristalização, pode ser diferenciado do $\mathrm{Pb}$ laboratorial, caso haja uma certa regularidade e controle deste último. As amostras da série 222 (Figura 15) indicam que o Pb laboratorial é abaixo de 10 pg e o Pb inicial incorporado nos cristais de zircão é próximo de zero. Porém, existem casos onde este é significativamente elevado, como é o caso da série 223 (Figura 15). Na série 223 verifica-se que existe um aumento na quantidade de $\mathrm{Pb}$ inicial em função da quantidade de peso dos cristais, ou seja, a quantidade de $\mathrm{Pb}$ inicial está intimamente relacionada com a quantidade de massa da amostra. Os cálculos das correções de Pb inicial e laboratorial são feitos através de programa PBDAT que se encontra no Anexo 1. 

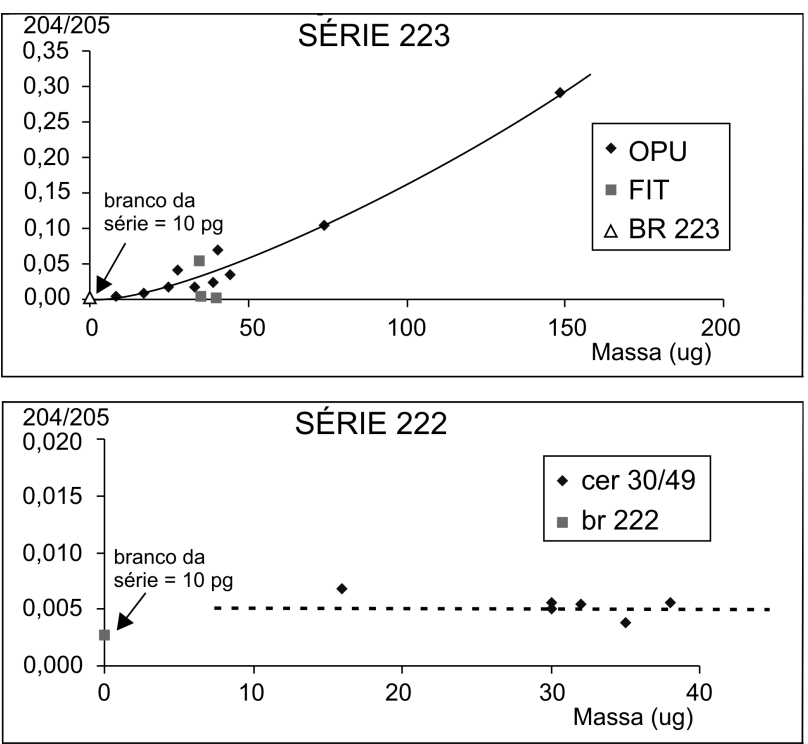

Figura 15. Intensidade da razão ${ }^{204} \mathrm{~Pb} /{ }^{205} \mathrm{~Pb}$ em função das massas dos cristais analisados. Cada ponto refere-se a uma fração de zircão das amostras OPU e FIT para ataque químico da série 223 (branco BR223) e amostra de zircão cer30 para ataque da série 222 (branco br222). A quantidade de ${ }^{205} \mathrm{~Pb}$ adicionado para cada experimento foi constante de 147 pg. Para a série 222 o $\mathrm{Pb}$ comum presente nos cristais é desprezível, enquanto que a série 223 mostra uma quantidade considerável de $\mathrm{Pb}$ inicial que aumenta com o peso dos zircões analisados.

\section{Precisão e sensibilidade dos espectrômetros de massa}

Os espectrômetros modernos são altamente sensíveis e podem captar feixes de íons com quantidades da ordem de 0,1 pg, quando é utilizado o amplificador de multiplicador de elétrons. A precisão requerida depende da aplicação que se quer dos resultados. Por exemplo, no método geocronológico Sm-Nd necessita-se de uma precisão menor que $0,003 \%$ na razão ${ }^{143} \mathrm{Nd} /{ }^{144} \mathrm{Nd}$. No método geocronológico U-Pb em zircão, a razão ${ }^{207} \mathrm{~Pb} /{ }^{206} \mathrm{~Pb}$ deve ser menor que $0,1 \%$ após a correção de fracionamento. Para obter tal precisão existe um limite mínimo (200 pg) de Pb que deve ser depositado no filamento caso o "branco" laboratorial seja da ordem de 5 a 10 pg. Com o uso das microcolunas de troca iônica, nem sempre grandes quantidades de materiais resultam em boas emissões de feixes iônicos (Figura 16). A eficiência da ionização de $\mathrm{Pb}$ e U depende do efeito matricial, isto é, a quantidade de matriz reduz o fator de ionização por efeito térmico no filamento. Para rochas jovens (por exemplo, fanerozóicas), nos quais a quantidade de $\mathrm{Pb}$ radiogênico é muito pequena, necessita-se entre 60 e $150 \mu \mathrm{g}$ de zircão e, neste caso, é importante que se passe a amostra duas vezes na microcoluna para minimizar o efeito matricial, caso contrário, deve-se utilizar uma coluna de troca iônica de altura maior.

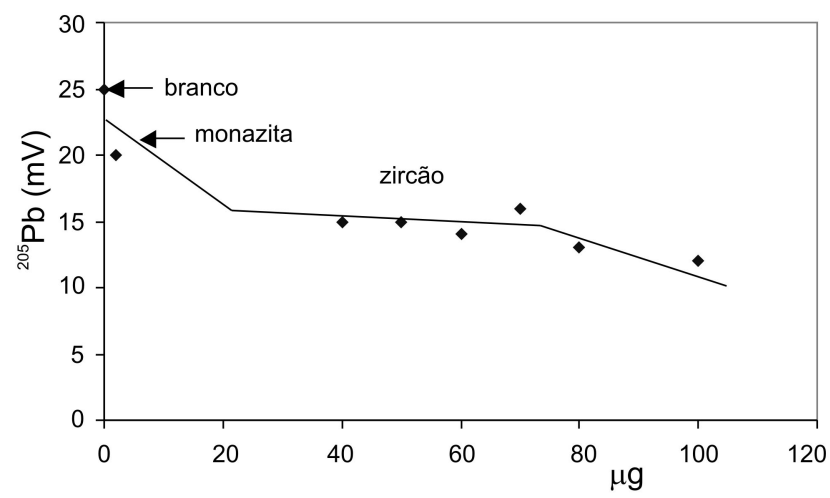

Figura 16. Intensidade do spike ${ }^{205} \mathrm{~Pb}$ em função do peso dos cristais. Para este experimento foi adicionado o spike ${ }^{205} \mathrm{~Pb}$, com uma quantidade fixa de $147 \mathrm{pg}$. À medida que a massa aumenta também aumenta a matriz, o que faz diminuir a intensidade do ${ }^{205} \mathrm{~Pb}$.

\section{APLICAÇÃO}

A seguir, serão apresentadas aplicações do método geocronológico U-Pb em zircão, tomando-se como exemplo as amostras coletadas nas pedreiras Atuba e Ita (Complexo Atuba), próxima à cidade de Curitiba - PR.

O Complexo Atuba localiza-se entre os fragmentos cratônicos Luis Alves e Paranapanema. Este complexo é caracterizado principalmente por gnaisses migmatíticos bandados (mesossoma de biotita-anfibólio gnaisses e leucossoma tonalítico-granodiorítico), gnaisses graníticos bandados, leucogranitos, biotita gnaisses lepidoblásticos e anfibolitos. Os afloramentos estudados mostram mobilizados de composição granítica-granodiorítica que ocorrem como bandas centimétricas a métricas, normalmente concordantes com o bandamento gnáissico regional. Também ocorrem rochas máfico-ultramáficas e xistos magnesianos com diferentes formas e dimensões associados aos gnaisses migmatíticos. As porções mesocráticos dos gnaisses bandados são compostas por hornblenda, plagioclásio (albita-oligoclásio), quartzo e biotita, podendo ocorrer adicionalmente diopsídio e/ou hiperstênio e granada. Os acessórios comuns são allanita, titanita, zircão, apatita e minerais opacos. Uma estruturação geral NE caracteriza os litotipos deste domínio e corresponde a uma foliação paralela ao bandamento gnáissico. As caracte- 
rísticas estruturais sugerem deformação principalmente controlada por cisalhamento dúctil, com rotação de feldspato e forte estiramento mineral. Na maioria das unidades do Complexo Atuba, os mergulhos da foliação Sn são relativamente elevados, variando, ora para NW, ora para SE.

As principais referências bibliográficas disponíveis na literatura especializada, referentes à geologia e mais especificamente à geocronologia deste complexo, referem-se a Perrota e Morais (1992), Machiavelli et al. (1993), Siga Jr. (1995), Basei et al. (1999), Harara (2001), Kaulfuss (2001), Sato et al. (2003), Silva (2005), entre outros.

Como exemplo da metodologia U-Pb em zircão, abordaremos os dados obtidos nos mesossomas da pedreira Atuba.

\section{Idades U-Pb SHRIMP em zircão da Pedreira ITA obtidas anteriormente}

O SHRIMP é um espectrômetro de massa de alta resolução acoplado a uma microssonda iônica. Permite efetuar análises isotópicas de U e Pb de zircão “in situ” e, portanto, a datação de zircão que apresente multifases de crescimento. Para isto, necessita-se de um estudo prévio de catodoluminescência (CL).

A Figura 17a refere-se a imagens CL cristais de zircão de diversas tipologias e hábitos, concentrados de rocha migmatítica (mesossoma) da pedreira de Atuba (Complexo Atuba). Deste conjunto foram realizadas 5 datações em 4 cristais, a
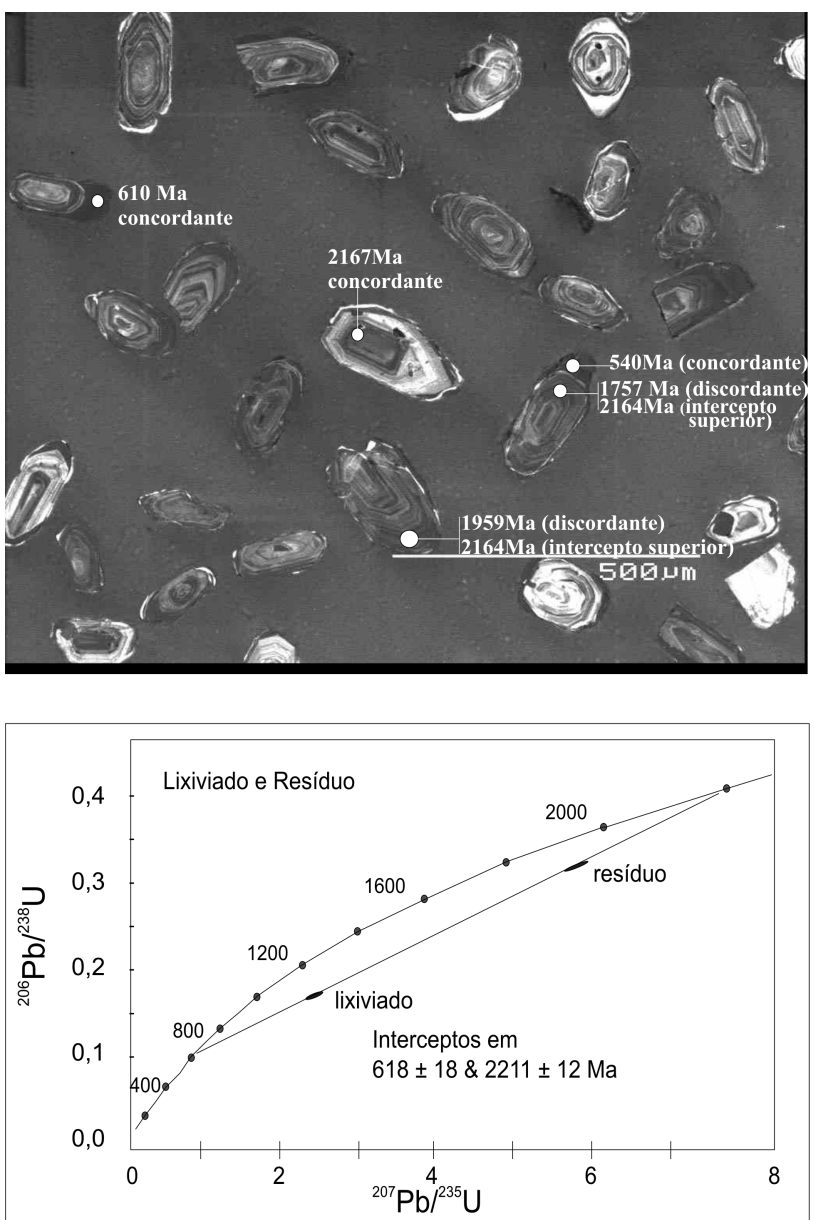

C b
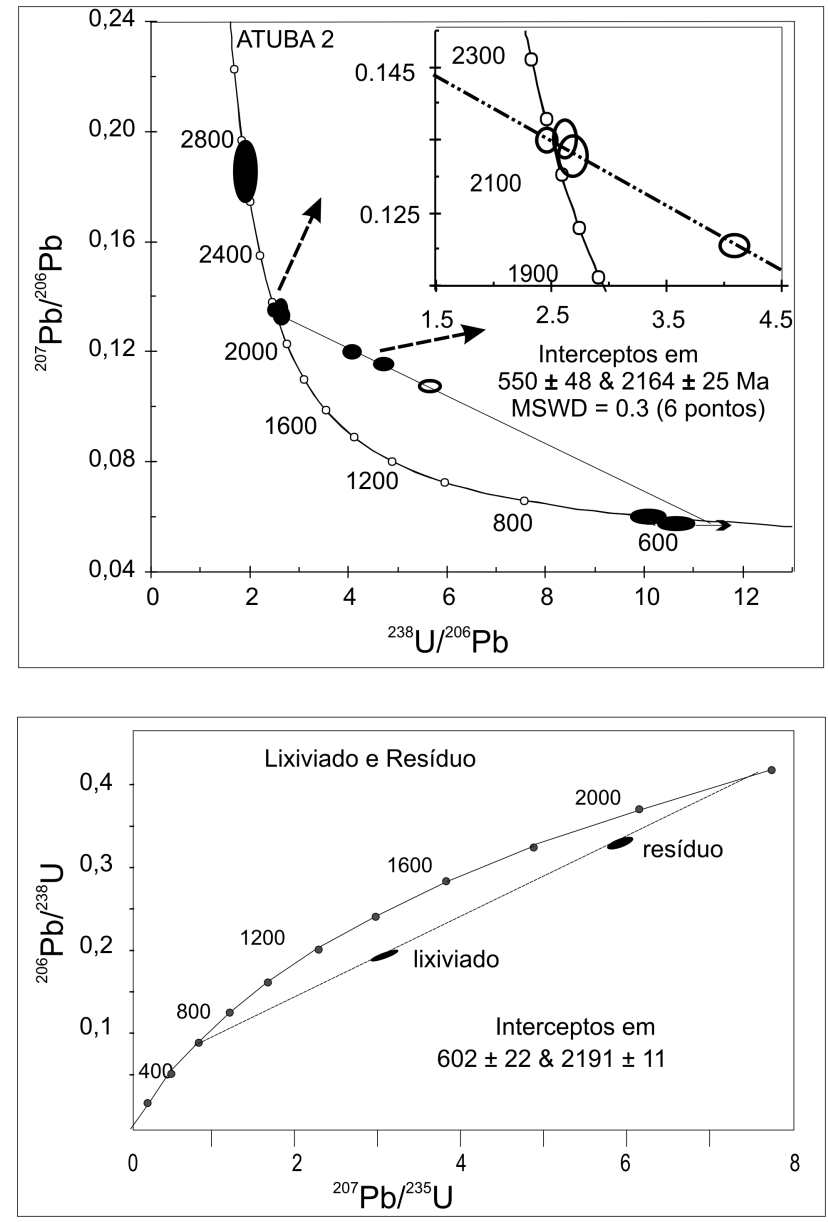

d

Figura 17. a. Imagens de catodoluminescência dos cristais de zircão de várias tipologias e de hábitos da pedreira lta, Complexo Atuba. A escolha dos cristais é de suma importância. Normalmente o local de análise deve apresentar bandas de zoneamentos regulares, pois nas áreas difusas são indicativas da ocorrência de perturbação. Os números, assinalados nos quatros cristais datados, são idades ${ }^{207} \mathrm{~Pb} /{ }^{206} \mathrm{~Pb}$. b. Diagrama de TeraWasserburg. c e d. Diagramas de concórdias. 
sendo 3 núcleos e 2 bordas de sobrecrescimento. As idades assinaladas na Figura 17a são idades ${ }^{207} \mathrm{~Pb} /{ }^{206} \mathrm{~Pb}$ (equação 9).

No diagrama de TeraWasserburg (Figura 17b) observa-se três conjuntos de pontos concordantes (2700, 2164 e $600 \mathrm{Ma}$ ) e três discordantes. A idade arqueana de $2700 \mathrm{Ma}$ indica o evento de formação da rocha mesossomática, muito próxima à época de acreção manto-crosta (idade modelo Sm-Nd, $\mathrm{T}_{\mathrm{DM}}$, de 2700 Ma; Sato et al., 2003). A migmatização paleoproterozóica e a remigmatização neoproterozóica é caracterizada através dos pontos concordantes com idades de 2164 Ma e $610 \mathrm{Ma}$ (Sato et al., 2003). Embora ambas idades das bordas dos cristais de zircão sejam concordantes no método U-Pb ( em $610 \mathrm{Ma}$ ), uma delas apresenta uma idade ${ }^{207} \mathrm{~Pb} /{ }^{206} \mathrm{~Pb}$ de 540 Ma. Os três pontos discordantes (Figura 17b), obtidos em análises dos núcleos, se alinham em uma reta que cruza em dois pontos da curva concórdia, interceptos superior e inferior. A idade obtida para o intercepto superior coincide ao conjunto de três pontos concordantes (2164 Ma), enquanto a idade do intercepto inferior cruza a curva de concórdia em $550 \mathrm{Ma}$ indicando uma idade ${ }^{207} \mathrm{~Pb} /{ }^{206} \mathrm{~Pb}$ neoproterozóica. A idade U-Pb de 600 Ma parece estar associada à formação do super continente Gondwana, enquanto a idade ${ }^{207} \mathrm{~Pb} /{ }^{206} \mathrm{~Pb}$ de 540 Ma (borda do zircão), bem como a idade de 550 Ma (intercepto inferior), pode estar associada à perda de $\mathrm{Pb}$ e, aparentemente, sem significado geológico.

\section{Idades U-Pb em zircão obtidas pelo método convencional (TIMS)}

As Figuras 17c e 17d representam diagramas concórdia contendo pontos relativos a lixiviados e resíduos obtidos através de digestão química convencional de cristais de zircão do Complexo Atuba. Os lixiviados referem-se às porções provenientes principalmente de bordas do zircão (atacado em forno de microondas), e plotam na porção inferior da linha de discórdia, enquanto que os resíduos (atacados em bombas a $200^{\circ} \mathrm{C}$ ), que são a grande maioria materiais dos núcleos de cristais, plotam na porção superior da linha discórdia. Os interceptos superiores indicam idades de 2191 e 2211 Ma, portanto, muito próximas aos dados obtidos nos núcleos de zircão analisados por SHRIMP. Do mesmo modo, os interceptos inferiores indicam idades U-Pb de 618 e 602 Ma (Sato et al., 2006), também muito próximas às idades obtidas "in situ” por SHRIMP.

O método de digestão química parcial se mostra extremamente útil na datação de zircão com apenas duas fases de crescimento, um núcleo e uma borda. Quando as bordas de sobrecrescimento são inferiores a $10 \mu \mathrm{m}$, a sonda iônica SHRIMP não pode ser utilizada, devido ao diâmetro feixe (tipicamente $30 \mu \mathrm{m}$ ). Portanto, a técnica de lixiviamento através de digestão química controlada (TLDQC) torna-se um importante método alternativo na datação através do método U-Pb, utilizando-se espectrômetro de massa do tipo TIMS. O TLDQC, no entanto, é um método limitado, pois, nem sempre permite datar com precisão a borda e o núcleo de zircão, sendo fundamental o estudo prévio da imagem de catodoluminescência.

Outra forma de datação de zircão realizada no GPGeoIGc/USP refere-se ao processo de evaporação de $\mathrm{Pb}$ (EVPb) com aquecimento por passo ("step heating”). As razões isotópicas medidas são ${ }^{207} \mathrm{~Pb} /{ }^{206} \mathrm{~Pb}$ e ${ }^{204} \mathrm{~Pb} /{ }^{206} \mathrm{~Pb}$, que são utilizadas para calcular $\left({ }^{207} \mathrm{~Pb} /{ }^{206} \mathrm{~Pb}\right)_{\text {rad }}$ com base na equação 9, e para o cálculo da idade utiliza-se a equação 8. As Figuras $18 \mathrm{a}$ e $18 \mathrm{~b}$ mostram as variações da razão ${ }^{207} \mathrm{~Pb} /{ }^{206} \mathrm{~Pb}$ em função do incremento de temperatura. O processo utilizado de evaporação-ionização foi direto, isto é, empregando-se um único filamento de rênio (Gentry et al., 1982) e não pela técnica de filamento duplo (Kober, 1986). A razão ${ }^{207} \mathrm{~Pb} /{ }^{206} \mathrm{~Pb}$ (Figura 18a) mostra inicialmente uma mistura de $\mathrm{Pb}$ da borda (provavelmente de idade neoproterozóica) com o núcleo paleoproterozóico. Na fase inicial de aquecimento (zonas de borda do zircão) é extremamente difícil separar-se o $\mathrm{Pb}$ comum adsorvido no cristal do $\mathrm{Pb}$ radiogênico, principalmente quando as bordas são pouco espessas $(<5 \mu \mathrm{m})$ e idades jovens e mesmo neoproterozóicas, uma vez que a quantidade de $\mathrm{Pb}$ radiogênico presente no cristal é extremamente baixa. À medida em que a temperatura é aumentada, o

a
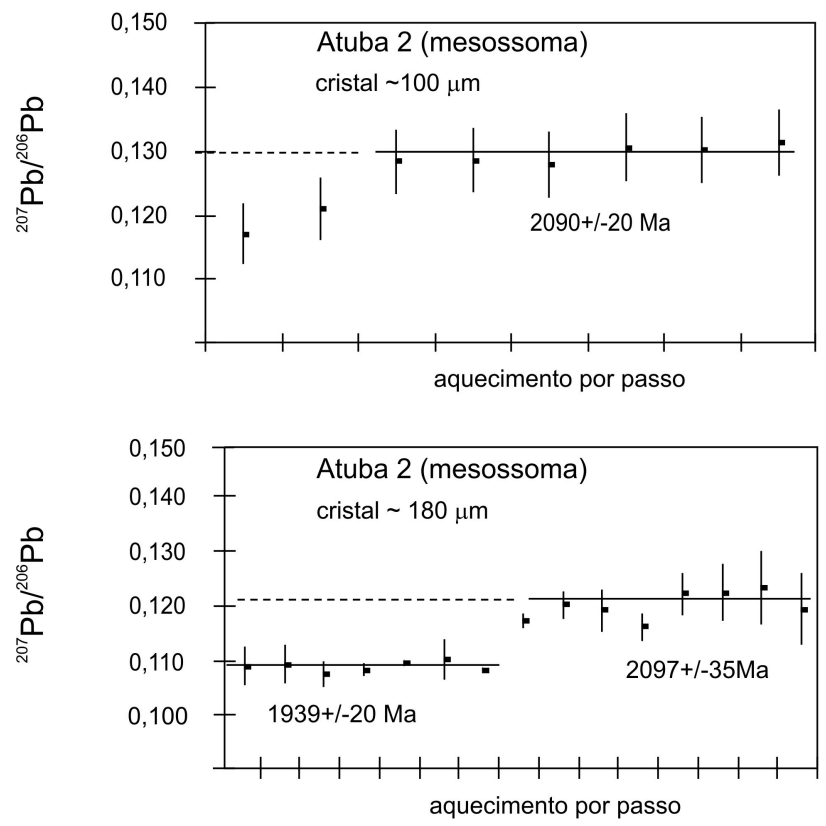

Figura 18. Histograma da razão ${ }^{207} \mathrm{~Pb} /{ }^{206} \mathrm{~Pb}$, obtido por evaporação de $\mathrm{Pb}$ por aquecimento por passo a partir de mono cristal de zircão, utilizando espectrômetro de massas TIMS (Sato et al., 2003). 
Pb proveniente das porções mais internas do zircão (núcleo) é evaporado. O diagrama apresenta um patamar (mínimo de 5 pontos) com razão ${ }^{207} \mathrm{~Pb} /{ }^{206} \mathrm{~Pb}$ igual a 0,130 , o que equivale a uma idade $\mathrm{Pb}-\mathrm{Pb}$ de $2090 \pm 20 \mathrm{Ma}$. No diagrama da Figura 18b não se observa nenhuma evidência de borda neoproterozóica, e sim patamares de idades paleoproterozóicas. O primeiro indica uma idade de $1939 \pm 20$ Ma e o segundo de $2097 \pm 35 \mathrm{Ma}$, possivelmente relativos à borda e ao núcleo do cristal, respectivamente. Os dados relativos aos núcleos, nos dois casos apresentados (Figuras 18a e $18 \mathrm{~b})$, indicam idades próximas às obtidas por SHRIMP. As pequenas diferenças observadas nas idades entre EVPb e SHRIMP podem estar relacionadas a distintos processos analíticos. O SHRIMP realiza uma análise pontual “in situ”, enquanto o EVPb, abrange toda a área do cristal em contacto com o filamento (Figura 11b). Os dados isotópicos ${ }^{207} \mathrm{~Pb} /{ }^{206} \mathrm{~Pb}$ obtidos por EVPb, portanto, são dependentes da forma da estrutura do crescimento do cristal. Isto é, se o sobrecrescimento apresenta-se de forma muito irregular, o $\mathrm{Pb}$ evaporado pode representar uma mistura de diferentes sítios do retículo cristalino. O processo de metamictização é outro fator que pode alterar a idade, já discutida anteriormente (Materiais Utilizados no Método Geocronológico U-Pb).

\section{Estudos da gênese do zircão com base na geoquímica isotópica de $\mathrm{Hf}$ - pedreira Ita - Complexo Atuba}

Os resultados geocronológicos obtidos para os mesossomas da pedreira Ita indicam a presença de material acrescido do manto para a crosta continental durante o Arqueano (3200 - 3000 Ma, idades U-Pb em zircão, idades modelo Sm-Nd, $\mathrm{T}_{\mathrm{DM}}$ ) onde os valores e $\varepsilon_{\mathrm{Nd}}$ e $\varepsilon_{\mathrm{Hf}}$ são positivos. Essas rochas foram intensamente migmatizadas durante o Paleoproterozóico (2200 - 1950 Ma, idade U-Pb em zircão) e remigmatizadas no Neoproterozóico (610 - $550 \mathrm{Ma}$ - idades U-Pb em zircão) (Sato et al., 2007). Os registros de idades arqueanas predominam nos mesossomas dos migmatitos, enquanto as idades paleoproterozóicas se concentram principalmente nas bordas dos cristais de leucossomas claros. Os valores de $\varepsilon_{\mathrm{Hf}}$ são positivos nos núcleos de cristais arqueanos, concentrados das rochas leucossomáticas claras, sugerindo a presença material juvenil derivado diretamente do manto nesta época. Nas bordas sobrecrescidas no Paleoproterozóico, os valores de $\boldsymbol{\varepsilon}_{\mathrm{Hf}}$ são negativos, sugerindo material com fonte crustal. Os registros neoproterozóicos foram obtidos principalmente nas bordas sobrecrescidas dos cristais concentrados das rochas leucossomáticas rosadas, que denotam uma intensa mobilização de U e Pb. Este período também foi acompanhado de intrusões de rochas dioríticas juvenis (dados U-Pb em zircão e $\varepsilon_{\mathrm{Hf}}$ próximo de zero) (Sato et al., 2007).

\section{CONSIDERAÇÕES FINAIS}

O método geocronológico U-Pb em zircão utilizando o TIMS tem alcançado no CPGeo qualidade comparável aos obtidos em laboratórios avançados. O emprego deste método utilizando a digestão química e o TIMS, no entanto, apresenta limitações, principalmente quando os cristais de zircão têm mais de uma fase de crescimento. O emprego de SHRIMP e/ou LA-ICP-MS constitui avanços tecnológicos importantes, estando em fases de instalações no CPGeo. Estes dois equipamentos executam análises isotópicas de U e Pb “in situ” em zircão. O LA-ICP-MS, além de efetuar a datação U-Pb em zircão, permite também análises geoquímicas, por exemplo, medidas isotópicas ${ }^{176} \mathrm{Hf} /{ }^{177} \mathrm{Hf}$, nos quais o valor de $\varepsilon_{\mathrm{Hf}}$ pode indicar o ambiente da formação no ponto do cristal analisado.

\section{AGRADECIMENTOS}

Os autores estão profundamente gratos ao revisor anônimo pelas sugestões valiosas e ao colega Moacyr José Buenano Macambira pela minuciosa correção do manuscrito.

\section{REFERÊNCIAS BIBLIOGRÁFICAS}

BASEI, M.A. S.; SIGA JR., O.; SATO, K.; SPROESSER, W. M. A metodologia Urânio-Chumbo na Universidade de São Paulo: princípios metodológicos, aplicações e resultados obtidos. Anais da Academia Brasileira de Ciência, v. 67, n. 2, p. 221-237, 1995.

BASEI, M. A. S.; SIGA JR., O.; REIS NETO, J. M.; PASSARELLI, C. R.; PRAZERES, H. J.; KAULFULL, G.; SATO, K.; LIMA, P. S. Paleoproterozoic granulitic belts of the Brazilian southern region (PR-SC). SOUTHAMERICAN SYMPOSIUM ON ISOTOPE GEOLOGY, 2., 1999, Cordoba. Extended Abstracts... Cordoba: Instituto de Geologia y Recursos Minerales, 1999. p. 291-294.

BOWSLES, J. F. W. Age dating of individual grains of uraninite in rocks from electron microprobe analyses. Chemical Geology, v. 83, p. 47-53, 1990.

CURY, L. F.; KAULFUSS, G; SIGAJR., O.; BASEI, M.A. S.; HARARA, O. M.; SATO, K. Idades U-Pb (Zircões) de 1.75Ga em granitóides alcalinos deformados dos Núcleos Betara e Tigre: evidências de regimes extensionais do Estateriano na Faixa Aipaí. Geologia USP: Série Científica, São Paulo, v. 2, p. 95-108, 2002.

FAURE G. Principles of isotope geology. New York: John Wiley \& Sons, 1988. 589 p. 
FAURE, G.; MENSING, T. M. Isotopes principles and applications. 3. ed. Hoboken: John Willey \& Sons, 2005. 897 p.

FRENCH, J. E.; HEAMAN, L. M.; CHACKO, T. Feasibility of chemical U-Th-total $\mathrm{Pb}$ baddeleyite dating by electron microprobe. Chemical Geology, v. 188, n. 1-2, p. 85-104, 2002.

GENTRY R. V.; SWORKI, T. J.; MCKOWN, H. S.; SMITH, D. H.; EBY, R. E.; CHRISTIE, W. H. Diferential lead retention in izricon: implications for nuclear waste containment. Science, v. 216, p. 296-297, 1982.

HARARA, O. M. Mapeamento e investigação petrológica e geocronológica dos litotipos da região do alto Rio $\mathrm{Ne}$ gro (PR-SC): Um exemplo de sucessivas e distintas atividades magmáticas durante o Neoproterozóico III. 2001. 206 f. Tese (Doutorado) - Instituto de Geociências, Universidade de São Paulo, 2006.

KAULFUSS, G. Geocronologia dos núcleos de embasamento Setuva, Betara e Tigre, Norte de CuritibaPR. 2001.115 f. Tese (Mestrado) - Instituto de Geociências, Universidade de São Paulo, São Paulo, 2001.

KERSCHOFER, L.; SCHARER, U.; DEUTTCH,A. Evidence for crustal from the lower mantle: baddeleyite megacrsyts of the Mbuji Muyi kimberlite. Earth and Planetary Science Letters, v. 179, p. 219-225, 2000.

KOBER, B. Whole-grain evaporation for 207Pb/206Pb-ageinvestigations on single single zircon using a double-filament thermal ion source. Contributions to Mineralogy and Petrology. v. .93, p. 482-490, 1986.

KOHN, J. K.; MALLOY, M. A. Formation of monazite via prograde metamorphic reactions among common silicates: implications for age determinations. Geochimica et Cosmochimica Acta, v. 68, n. 1, p. 101-113, 2004.

LOIOS, V. A. P. Laboratório de preparação e separação de minerais - Centro de Pesquisas Geocronológicas - IGc-USP. In: SIMPÓSIO DE 40 ANOS DE GEOCRONOLOGIA NO BRASIL, 2004, São Paulo. Boletim de resumos... São Paulo: CPGeo/IGc/USP, 2004. p. 23.

MACHIAVELLI, A.; BASEI, M. A. S.; SIGA JR., O. O suíte granítico Rio Piên: um arco magmático do proterozóico superior no micro placa Curitiba. Geochimica Brasiliensis, v. 7, n. 2, p.113-129, 1993.

PERROTA, M. M.; MORAIS, S. M. Asuíte magerito-norítica. In:CONGRESSOBRASILEIRODEGEOLOGIA, 37., 1992, São
Paulo. Resumos... São Paulo: SBG, 1992.p. 417.v. 1.

SATO, K.; SIGA JR., O.; NUTMAN, A. P.; BASEI, M. A. S.; MCREATH, I.; KAULFUSS, G. The Atuba Complex, Southern South American Platform: archean components and paleoproterozoic to neoproterozoic tectonothermal events. Gondwana Research, v. 6, n. 2, p. 251-263, 2003.

SATO, K.; KAWASHITA, L. Espectrometria de massa em geologia isotópica. Geologia USP: Série Científica, São Paulo, v. 2, p. 57-77, 2002.

SATO, K.; SONOKI, M.; FRANCISCO, R. C.; KAWASHITA, K. Espectrometria de massa por ionização térmica (TIMS) CPGeo-IGc-USP. In: SIMPÓSIO DE 40 ANOS DE GEOCRONOLOGIA NO BRASIL, 2004, São Paulo. Boletim de resumos... São Paulo: CPGeo/IGC/USP, 2004. p. 20.

SATO, K.; SIGA JR., O.; BASEI, M. A. S.; SPROESSER, W. M. Leaching technique: alternative solution for U-Pb dating of overgrown zircons. In: SOUTH AMERICAN SYMPOSIUM ON ISOTOPE GEOLOGY, 5., 2006, Punta del Este. Proceedings...Buenos Aires: Idea Gráfica, 2006. p. 34-37.

SATO, K. Espectrometria de massa - MAT 262. Manual Interno do Centro de Pesquisas Geocronológicas do IGc. São Paulo: USP, 2007. 26 p.

SATO, K.; SIGA JR., O.; SILVA, J.; MCREATY, I.; IIZUKA, T.; RINO, S.; HIRATA, T.; SPROESSER, M. W.; BASEI, M. A. S. Estudo da gênese do zircão com base em geoquímica isotópica de Hf: um exemplo da evolução crustal da Pedreira Ita (Complexo Atuba) - PR com base nos dados de $\varepsilon_{\mathrm{Hf}}$. In: CONGRESSO BRASILEIRO DE GEOQUÍMICA, 11., 2007, Atibaia. Anais...Atibaia: Sociedade Brasileira de Geoquímica, 2007.(CD-ROM).

SPROESSER, W. M; PASSARELLI, C. R.; MORAES, M. C. de. Método U-Pb - CPGeo - IGc - USP. In: SIMPÓSIO DE 40 ANOS DE GEOCRONOLOGIA NO BRASIL, 2004, São Paulo. Boletim de resumos... São Paulo: CPGeo/IGC/USP, 2004. p. 26.

STACEY, J. S.; KRAMERS, J. D. Approximation of terrestrial lead isotope evolution by a two-stage model. Earth and Planetary Science Letters, v. 26, p. 207-221, 1975.

SIGA JR., O. Domínios tectônicos do sudeste do Paraná e noroeste de Santa Catarina: geocronologia e evolução crustal. 1995. 212 f. Tese (Doutorado) - Instituto de Geociências, Universidade de São Paulo, SP, 1995. 
SILVA, J. A. Petrologia e geoquímica dos gnaisses migmatíticos do Complexo Atuba, Curitiba - PR. 2005. 140 f. Tese (Mestrado) - Instituto de Geociências, Universidade de São Paulo, 2005.
VLACH, S. R. F. Geocronologia de minerais acessórios pelo método U-Th-Pb total com microssonda eletrônica: monazita, torita, xenotima e uraninita. São Paulo: Departamento de Mineralogia e Geotectônica - IGc/USP, 2001. 82 p. (Manual interno).

\section{ANEXOS}

\section{Anexo 1: fórmulas matemáticas utilizadas no PBDAT}

As fórmulas apresentadas a seguir foram deduzidas pelos autores deste trabalho e testadas com exemplos numéricos reais e os resultados obtidos conferem com os valores obtidos quando utilizado o programa PBDAT.

\begin{tabular}{cccccc}
\hline \multicolumn{5}{c}{ Dados utilizados de Pb } \\
\hline Isótopos e razões & Massa exata & $\begin{array}{c}\text { Pb comum } \\
\text { Tabela }\end{array}$ & $\begin{array}{c}\text { Pb comum } \\
\text { PBDAT }\end{array}$ & Isótopos e razões & Spike ${ }^{205}$ Pb (CPGeo) \\
\hline 204 & 203,973037 & 1,37 & 1,3566 & 204 & $0,0079 \%$ \\
205 & 204,9750 & & & 205 & $99,666 \%$ \\
206 & 205,9744 & 25,15 & 25,315 & 206 & $0,0827 \%$ \\
207 & 206,9759 & 21,11 & 21,25 & 207 & $0,0727 \%$ \\
208 & 207,9766 & 52,38 & 52,082 & 208 & $0,1704 \%$ \\
$206 / 204$ & & 18,35 & 18,66 & $204 / 205$ & 0,00008 \\
$206 / 207$ & & 1,191 & $206 / 205$ & 0,00083 \\
$206 / 208$ & & 0,480 & & $207 / 205$ & 0,00073 \\
& & & $208 / 205$ & 0,00171 \\
Peso atômico & & & & 207,9696 \\
\hline
\end{tabular}

\begin{tabular}{cccc}
\hline \multicolumn{2}{c}{ Dados utilizados de U } \\
\hline Massa e razão & Massa exata & Abundância e razão & Spike $^{235}$ U \\
\hline 234 & 234,04095 & $0,0055 \%$ & 1,6663 \\
235 & 235,04392 & $0,720 \%$ & 97,6617 \\
236 & 236,045 & $0,000 \%$ & 0,14909 \\
238 & 238,05078 & $99,2745 \%$ & 0,52289 \\
$238 / 235$ & & 99,2745 & 0,005354 \\
Peso atômico & & 238,0289 & 235,0256 \\
\hline
\end{tabular}




\section{Constantes utilizadas}

- Fator de normalização de $\mathrm{Pb}=0,10 \%$ u.m.a. (unidade de massa atômica)

- Conc. de spike $205=7,16310^{-11}$ moles $/ \mathrm{g}$

- Conc. de spike $205=14,68310^{-9} \mathrm{~g} / \mathrm{g}$

- Conc. de spike $235=5,24810^{-9} \mathrm{moles} / \mathrm{g}$

- Conc. de spike $235=1233,610^{-9} \mathrm{~g} / \mathrm{g}$

- "Branco" de Pb comum = medido para cada série

- "Branco" de U = desprezível

- Peso de amostra = variável (gramas)

- Peso de spike $=0,010$ gramas $(10 \mu \mathrm{l})$

\section{Principais equações utilizadas no PBDAT:}

$\cdot 206_{\mathrm{r}}=206_{\mathrm{m}}-206_{\mathrm{c}}-206_{\mathrm{i}}$

$\cdot 207_{\mathrm{r}}=207_{\mathrm{m}}-207_{\mathrm{c}}-207_{\mathrm{i}}$

- $(206 / 207)_{\mathrm{z}}=\left[(206 / 205)_{\mathrm{m}}-(206 / 205)_{\mathrm{c}}\right] /\left[(207 / 205)_{\mathrm{m}}-(207 / 205)_{\mathrm{c}}\right]$

- $(206 / 208)_{\mathrm{z}}=\left[(206 / 205)_{\mathrm{m}}-(206 / 205)_{\mathrm{c}}\right] /\left[(208 / 205)_{\mathrm{m}}-(208 / 205)_{\mathrm{c}}\right]$

- $(206 / 204)_{\mathrm{z}}=\left[(206 / 205)_{\mathrm{m}}-(206 / 205)_{\mathrm{c}}\right] /\left[(204 / 205)_{\mathrm{m}}-(204 / 205)_{\mathrm{c}}\right]$

onde $\mathrm{m}=$ medido, $\mathrm{c}=\mathrm{Pb}$ comum; $\mathrm{i}=\mathrm{Pb}$ inicial; $\mathrm{r}=\mathrm{Pb}$ radiogênico

- $(206 / 205)_{\mathrm{c}}=\left(\mathrm{Ab}_{206} \times \mathrm{B}_{\mathrm{r}}\right) /\left(\mathrm{C}_{\mathrm{s}} \times \mathrm{P}_{\mathrm{s}}\right)$

$\cdot(207 / 205)_{\mathrm{c}}=\left(\mathrm{Ab}_{207} \times \mathrm{B}_{\mathrm{r}}\right) /\left(\mathrm{C}_{\mathrm{s}} \times \mathrm{P}_{\mathrm{s}}\right)$

$\cdot(204 / 205)_{c}=\left(A_{204} \times B_{r}\right) /\left(C_{s} \times P_{s}\right)$

onde $\mathrm{Ab}=$ abundância; $\mathrm{C}_{\mathrm{s}}=$ concentração de spike; $\mathrm{P}_{\mathrm{s}}=$ massa de spike; $\mathrm{B}_{\mathrm{r}}=$ branco $(\mathrm{g})$ = variável equação de normalização; $\mathrm{f}=$ fator de normalização $=0,10 \%$ (u.m.a)

$\cdot\left(\mathrm{m}_{1} / \mathrm{m}_{2}\right)_{\mathrm{znor}}=\left(\mathrm{m}_{1} / \mathrm{m}_{2}\right)_{\mathrm{z}}\left(1+\delta_{\mathrm{m}} \mathrm{f}\right)$

onde $\mathrm{m}_{1}$ e $\mathrm{m}_{2}$ são massas dos isótopos e $\delta_{\mathrm{m}}=\mathrm{m}_{1}-\mathrm{m}_{2}$

\section{Cálculo de $\mathrm{Pb}$ em moles/g}

- $\mathrm{C}_{\mathrm{mi}(\mathrm{z})}=\left[\left(\mathrm{M}_{\mathrm{i}} / 205\right)_{\mathrm{znor}} \times \mathrm{C}_{\mathrm{s}} \times \mathrm{P}_{\mathrm{s}}\right] / \mathrm{P}_{\mathrm{am}}$ em moles/g

Peso atômico = soma de todas as massas levando em conta a ponderação das abundâncias

$\mathrm{P}_{\text {atômico }}=\Sigma\left(\mathrm{M}_{\mathrm{i}} \times \mathrm{A}_{\mathrm{i}}\right)$; onde $\mathrm{M}_{\mathrm{i}}=$ massa exata, e $\mathrm{A}_{\mathrm{i}}=$ abundância dos isótopos

- Conc (g/g) $=$ moles $_{206} \times \mathrm{P}_{\text {atômico }} /$ Abund $_{206}$

$\cdot \mathrm{Z}={ }^{235} \mathrm{U}_{\mathrm{N}} /{ }^{235} \mathrm{U}_{\mathrm{S}}=\left[(238 / 235)_{\mathrm{S}}-(238 / 235)_{\mathrm{m}}\right] /\left[(238 / 235)_{\mathrm{m}}-(238 / 235)_{\mathrm{N}}\right]$

$\cdot \mathrm{U}(\mathrm{g})=\left[\mathrm{Z} \mathrm{C}_{\text {spike235 }} \mathrm{P}_{\text {spike }} \mathrm{P}_{\text {atômico }}\right] / \mathrm{Ab}_{235}$

$\mathrm{U}_{\text {zircão }}=\mathrm{U}(\mathrm{g})-\mathrm{U}_{\mathrm{BR}}$

- $\mathrm{U}_{\text {zircão }}(\mathrm{ppm})=\mathrm{U}_{\text {zircão }} / \mathrm{P}_{\mathrm{am}}$

onde $\mathrm{U}_{\mathrm{BR}}=$ branco em g; $\mathrm{Ab}_{235}=$ abundância de ${ }^{235} \mathrm{U}_{\mathrm{N}} ; \mathrm{P}_{\mathrm{am}}=$ peso da amostra; $\mathrm{P}_{\mathrm{s}}=$ peso do spike;

$\mathrm{N}=$ natural; $\mathrm{S}=$ spike; $\mathrm{m}=$ medido

${ }^{\text {total }} \mathrm{U}=\mathrm{U}_{\mathrm{ppm}} / \mathrm{P}_{\mathrm{at}}$ (moles/g)

${ }^{235} \mathrm{U}={ }^{\text {total }} \mathrm{U} \times \mathrm{Ab}_{235}$

${ }^{238} \mathrm{U}={ }^{\text {total }} \mathrm{U} \times \mathrm{Ab}_{238}$

${ }^{206} \mathrm{~Pb}_{\mathrm{z}} /{ }^{238} \mathrm{U}=\alpha$

${ }^{207} \mathrm{~Pb}_{\mathrm{z}} /{ }^{235} \mathrm{U}=\beta$

${ }^{204} \mathrm{~Pb}_{\mathrm{z}} /{ }^{238} \mathrm{U}=\chi$

onde $\alpha, \beta, \chi$ são valores sem correção de $\mathrm{Pb}$ inicial

$\mathrm{R}=(207 / 206)_{\mathrm{r}}=(207 / 206)_{\mathrm{z}}+(204 / 206)_{\mathrm{z}} \mathrm{x} \frac{\left[(207 / 206)_{\mathrm{z}}-(207 / 206)_{\mathrm{i}}\right]}{\left[(204 / 206)_{\mathrm{i}}-(204 / 206)_{\mathrm{z}}\right]}$ 


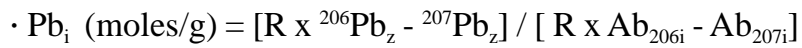

onde $\mathrm{Pb}_{\mathrm{i}}$ é $\mathrm{Pb}$ inicial total; ${ }^{206} \mathrm{~Pb}_{\mathrm{z}}=\mathrm{C}_{206 \mathrm{z}} \mathrm{e}{ }^{207} \mathrm{~Pb}_{\mathrm{z}}=\mathrm{C}_{207 \mathrm{z}}$ da equação 20

$\cdot \mathrm{Pb}_{\mathrm{i}}(\mathrm{g})=\mathrm{Pb}_{\mathrm{i}} \times \mathrm{P}_{\text {peso do branco }} \times \mathrm{P}_{\text {peso atômico }}$

- $\mathrm{Ab}_{204 \mathrm{i}} ; \mathrm{Ab}_{206 \mathrm{i}} ; \mathrm{Ab}_{207 \mathrm{i}} ; \mathrm{Ab}_{208 \mathrm{i}} \quad$ abundâncias relativas (com base na tabela Stacey e Kramer, 1975)

- total $\mathrm{Pb}_{\mathrm{i}}=\mathrm{Pb}_{\mathrm{i}}\left(\mathrm{n}^{\mathrm{o}}\right.$ de moles/g)

- ${ }^{206} \mathrm{~Pb}_{\mathrm{r}}={ }^{206} \mathrm{~Pb}_{\mathrm{z}}-{ }^{\text {total }} \mathrm{Pb}_{\mathrm{i}} \times \mathrm{Ab}_{206 \mathrm{i}}$

- ${ }^{207} \mathrm{~Pb}_{\mathrm{r}}={ }^{206} \mathrm{~Pb}_{\mathrm{z}}-{ }^{\text {total }} \mathrm{Pb}_{\mathrm{i}} \times \mathrm{Ab}_{207 \mathrm{i}}$

- ${ }^{208} \mathrm{~Pb}_{\mathrm{r}}={ }^{206} \mathrm{~Pb}_{\mathrm{z}}-{ }^{\text {total }} \mathrm{Pb}_{\mathrm{i}} \times \mathrm{Ab}_{208 \mathrm{i}}$

- total $\mathrm{U}($ moles $/ \mathrm{g})=\mathrm{U}_{\mathrm{ppm}} / \mathrm{P}_{\mathrm{at}}$

- ${ }^{235} \mathrm{U}$ (moles $\left./ \mathrm{g}\right)={ }^{\text {total }} \mathrm{U} \times \mathrm{Ab}_{235}$

. ${ }^{238} \mathrm{U}$ (moles/g) $={ }^{\text {total }} \mathrm{U} \times \mathrm{Ab}_{238}$

- ${ }^{206} \mathrm{~Pb}_{\text {rad }} /{ }^{238} \mathrm{U}=$ equação 27 / equação 32

- ${ }^{207} \mathrm{~Pb}_{\text {rad }} /{ }^{235} \mathrm{U}=$ equação 28 / equação 31

- $\mathrm{T}_{206}=\left(1 / \lambda_{1}\right) \operatorname{Ln}\left[\left({ }^{206} \mathrm{~Pb}_{\mathrm{rad}}{ }^{238} \mathrm{U}\right)+1\right]$ onde $\lambda_{1}=1,5512510^{-10}$

- $\mathrm{T}_{207}=\left(1 / \lambda_{2}\right) \operatorname{Ln}\left[\left({ }^{207} \mathrm{~Pb}_{\mathrm{rad}}{ }^{235} \mathrm{U}\right)+1\right]$ onde $\lambda_{2}=9,848510^{-10}$

$\cdot 207 / 206_{\mathrm{r}}=(1 / 137,88) \times \mathrm{e}^{\lambda 2 \mathrm{~T}}-1 / \mathrm{e}^{\lambda 1 \mathrm{~T}}-1 \quad$ idade ${ }^{207} \mathrm{~Pb} /{ }^{206} \mathrm{~Pb}$, onde $207 / 206_{\mathrm{r}}=$ equação 25

Observação: a correção de Stacey e Kramer (1975) deve de ser efetuada quando o Pb inicial foi incorporado no ato do fechamento do sistema. A presença de $\mathrm{Pb}$ inicial pode ser monitorada com o isótopo ${ }^{204} \mathrm{~Pb}$ que não é radiogênico. Normalmente, se a razão ${ }^{204} \mathrm{~Pb} / 206 \mathrm{~Pb}$ for menor que 0,0001, a correção de Stacey e Kramer (1975) tornar-se-á insignificante no recálculo de outros isótopos de $\mathrm{Pb}$ que são radiogênicos, porém, se a razão ${ }^{204} \mathrm{~Pb} /{ }^{206} \mathrm{~Pb}$ for da ordem de 0,01 indica que uma grande quantidade de $\mathrm{Pb}$ inicial foi incorporada na amostra e que foi somado com o $\mathrm{Pb}$ radiogênico produzido no decorrer do tempo geológico após o fechamento do sistema. A razão isotópica de Pb inicial é dependente de tempo geológico, portanto, esta correção deve ser feita em um processo interativo.

\section{Anexo 2: procedimento de eluição}

1. dissolver a amostra (processadas com $\mathrm{HF}, \mathrm{HNO}_{3}$ e $\mathrm{HCl} 6 \mathrm{~N}$ ) com $30 \mu \mathrm{l}$ de $\mathrm{HCl} 3 \mathrm{~N}$;

2. colocar resina eichron ( 1 x 8$)$ até o topo da parte estreita da coluna;

3. lavar a resina com $210 \mu \mathrm{l}$ (7 gotas) de $\mathrm{H}_{2} \mathrm{O}$ MILIQ;

4. lavar resina com $210 \mu \mathrm{l}$ ( 7 gotas) de $\mathrm{HCl} 6 \mathrm{~N}$;

5. condicionar resina com $120 \mu \mathrm{l}$ ( 4 gotas ) de $\mathrm{HCl} 3 \mathrm{~N}$;

6. depositar $30 \mu \mathrm{l}$ de amostra com micropipeta na coluna; escoar toda a solução;

7. lavar com $30 \mu \mathrm{l}$ (1 gota) de HCl 3N. Deixar passar tudo ( $\mathrm{T} \sim 4 \mathrm{~min}$.);

8. lavar com $60 \mu \mathrm{l}$ (2 gotas de $30 \mu \mathrm{l}$ ) de $\mathrm{HCl} 3 \mathrm{~N}$. Deixar passar tudo (T 6 min.);

9. lavar com $77 \mu \mathrm{l}$ ( 7 gotas de $11 \mu \mathrm{l})$ de $\mathrm{HCl} 6 \mathrm{~N}$;

10. colocar o copo de teflon (SAVILLEX ${ }^{\circledR}$ ) limpo;

11. coletar $\mathrm{U}$ e $\mathrm{Pb}$ com $300 \mu \mathrm{l}$ (10 gotas) de $\mathrm{H}_{2} \mathrm{O}$ MILIQ;

12. adicionar 1 gota $(11 \mu \mathrm{l})$ de $\mathrm{H}_{3} \mathrm{PO}_{4} \quad 0,1 \mathrm{~N}$ e secar até formar microgotas (pronto para espectrometria).

Observação: no caso de titanita, devido à grande quantidade matriz, deve ser passada duas vezes na microcoluna de troca iônica para melhorar a purificação de U e Pb. 